\title{
Comprehensive Review
}

\section{Neurostimulation for the Treatment of Chronic Head and Facial Pain: A Literature Review}

\author{
Ajay B. Antony, MD1, Anthony J. Mazzola, MD², Gurpreet S. Dhaliwal, MD², \\ and Corey W. Hunter, MD ${ }^{4}$
}

From: ${ }^{2}$ Department of Anesthesiology, University of Florida College of Medicine, Gainesville, FL; ${ }^{2}$ Department of Rehabilitation and Human Performance, Icahn School of Medicine at Mount Sinai, New York, NY; 3 SEVA Pain Institute,

Tracy, CA; ${ }^{4}$ Department of Rehabilitation and Human

Performance, Ainsworth, Institute of Pain Management, Icahn School of Medicine at

Mount Sinai, New York, NY

Address Correspondence: Ajay Antony, MD

Department of Anesthesiology University of Florida College of Medicine PO Box 100254 Gainesville, FL 32610

E-mail: aantony@anest.ufl.edu

Conflict of interest: Dr. Antony is a consultant for Abbott, is on the product advisory board for Boston Scientific, and has sponsored research (PI) with Abbott/Nevro. Dr. Hunter is a consultant and researcher for Abbott, Saluda, and Nuvectra, and was previously a consultant

for Nevro. Dr. Mazzola and

Dr. Dhaliwal do not have any conflicts of interest to report.

None of the authors of the

manuscript received any

remuneration. Further, the

authors have not received any reimbursement or honorarium in any other manner for the work on this manuscript.

Manuscript received: 12-19-2018 Accepted for publication: 03-29-2019

Free full manuscript: www.painphysicianjournal.com
Background: Head and facial pain is a common and often difficult to treat disorder. Routine treatments sometimes fail to provide acceptable relief, leaving the patient searching for something else, including narcotics and surgery. Recently, neuromodulation has been expanding to provide another option. Secondary to its potentially temporary nature and relatively manageable risk profile, several reviews have suggested trialing neuromodulation prior to starting narcotics or invasive permanent surgeries. There is evidence that neuromodulation can make a difference in those patients with intractable severe craniofacial pain

Objectives: To provide a basic overview of the anatomy, epidemiology, pathophysiology and common treatments of several common head and facial disorders. Furthermore, to demonstrate the suggested mechanisms of neuromodulation and the evidence currently existing for the use of neuromodulation.

Methods: A comprehensive review was performed regarding the available literature through targeting articles reporting on the use of neuromodulation to treat pain of the head and face.

Results: We compiled and discuss the current evidence available in treating head and facial pain. The strongest evidence currently for neuromodulation is for occipital nerve stimulation for migraine, transcutaneous vagal nerve stimulation for migraine and cluster headache, sphenopalatine ganglion microstimulation for cluster headache, and transcutaneous supraorbital and supratrochlear nerve stimulation for migraine. In addition, there is moderate evidence for occipital nerve stimulation in treating occipital neuralgia.

Limitations: Neuromodulation has been trialed and is promising in several craniofacial pain disorders; however, there remains a need for large-scale, randomized, placebo-controlled clinical trials to further evaluate the efficacy and safety of most treatments. Much of the current data relies on case reports without randomization or placebo controls.

Conclusions: With advancing techniques and technology, neuromodulation can be promising in treating intractable pain of the head and face. Although more randomized controlled trials are warranted, the current literature supports the use of neuromodulation in intractable craniofacial pain.

Key words: Neuromodulation, headache, facial pain, craniofacial pain, migraine, cluster headache, trigeminal neuralgia, occipital neuralgia, peripheral nerve stimulator, high cervical spinal cord stimulator, peripheral nerve field stimulator

Pain Physician 2019: 22:447-477 
$\mathbf{N}$

euromodulation is an ever-expanding field that has been used for the treatment of chronic pain disorders for the last 50 years. Although the predominant use of neurostimulation has been for the treatment of conditions such as failed back surgery syndrome, complex regional pain syndrome and the like, it has expanded over time to include pelvic pain (1), traumatic neuropathies, diabetic neuropathies, and postherpetic neuralgia (PHN) (2). Recent developments in waveform technology have brought promising potential advancements to the field (3). In addition to targeting dorsal column fibers via leads placed in the epidural space, tonic stimulation of both peripheral nerves and subcutaneous unnamed small fibers of peripheral nerves has been employed for pain control (2). As the understanding, technology, and proven efficacy of peripheral neurostimulation has improved, newer extracranial and intracranial modalities have shown promise in treating headache and facial pain. There is growing consensus among the pain community that extracranial and intracranial modalities be considered prior to starting chronic, longterm opioid therapies in certain conditions refractory to conservative medical management (4).

\section{Facial Anatomy/Innervation}

Headaches and facial pain can be difficult to diagnose and treat often because of the confluence of complex anatomic structures and sensory systems. The trigeminal cranial nerve ( $\mathrm{CN} V$ ) and its ophthalmic (CN V1), maxillary (CN V2), and mandibular (CN V3) divisions provide sensory innervation to the face via their cutaneous terminal branches. These branches relay sensory input and converge at the Gasserian ganglion (also known as trigeminal or semilunar ganglion) located in Meckel's cave (5). Cutaneous branches of each such as the supraorbital, infraorbital, and mental nerves can be targeted for various therapeutic interventions (4).

\section{Trigeminal Nerve}

The trigeminal nerve carries much of the general sensory information from the head, and also innervates the muscles that move the lower jaw. At the level of the middle cranial fossa, the sensory root forms the trigeminal ganglion that holds the cell bodies of these sensory neurons. Of note, the motor root lies below and separates proximal to this point. From the Gasserian ganglion arise the aforementioned 3 divisions of sensory nerves: the ophthalmic nerve, the maxillary nerve, and the mandibular nerve (6).

\section{Ophthalmic Nerve}

The ophthalmic division enters the orbit through the superior orbital fissure. It carries sensation from the cephalic part of the anterior face covering the skin from the nose, upper eyelids, upper bridge of nose, scalp, and forehead, as well as sensation from the cornea, mucosa of nasal cavity, and frontal paranasal sinuses. This nerve has various divisions (6).

The supraorbital and the supratrochlear nerves leave the orbit superiorly and are responsible for transmitting sensation from the eyelid, forehead, and scalp. The supraorbital nerve passes through the frontalis muscle and continues superiorly providing coverage over the anterior scalp to the vertex of the head. Similarly, the supratrochlear nerve passes through the frontalis and continues across the anterior forehead supplying the center of the forehead (7). Both these peripheral nerves have been targeted for pain relief as they are easily accessible at a location of maximal nociception where they superficially traverse under the subcutaneous tissue at the forehead (8).

\section{Maxillary Nerve}

The maxillary nerve exits the cranial cavity through the foramen rotundum and enters the pterygopalatine fossa. It supplies the skin including the upper lip, lower eyelid, upper teeth and gums, mucosa of the nose, maxillary and ethmoid sinuses, and palate (7).

The infraorbital nerve is a peripheral branch that exits the maxilla through the infraorbital foramen and provides sensation to the lower eyelid, cheek, side of the nose, and upper lip. Similarly, the zygomaticotemporal branch exits the zygomatic bone to supply sensation over the anterior temple located above the zygomatic arch (7).

\section{Mandibular Nerve}

The mandibular nerve passes through the foramen ovale as it emerges from the cranium. Of note, the motor component of the trigeminal nerve also exits through the foramen ovale, where it unites with the sensory division. This nerve transmits sensation from the skin over the mandible including the lower lip and side of head. In addition, it supplies the lower teeth and gums, temporomandibular joint (TMJ), mucosa of mouth, and anterior two-thirds of the tongue (6).

The auriculotemporal nerve, a collateral branch off of the posterior division of the mandibular nerve, enters the face just behind the TMJ. The nerve runs laterally to the mandible neck, passing anterior to the 
ear and continues cephalically to innervate the ear, the external auditory conduct, the external side of the tympanic membrane, and the temporal region. Furthermore, it innervates the TMJ and carries parasympathetic fibers to the parotid gland (7).

\section{Facial Nerve}

The facial nerve (CN VII) carries multiple nerve fibers. The nerve leaves the cranial cavity through the internal acoustic meatus and forms the geniculate ganglion. The general sensation is transmitted from the external acoustic meatus and deeper parts of the auricle. Taste sensation is provided from the anterior two-thirds of the tongue. Parasympathetic autonomic regulation is provided to the lacrimal gland, submandibular and sublingual salivary glands, and glands in the mucous membranes of the nasal cavity and palates. It is at the location of the geniculate ganglion where the facial nerve gives off the greater petrosal nerve that carries the majority of the parasympathetic fibers. The origin of the greater petrosal nerve is the sphenopalatine ganglion (SPG). Furthermore, the facial nerve innervates the muscles for facial expression (7).

\section{Glossopharyngeal Nerve}

Glossopharyngeal nerve ( $\mathrm{CN} I \mathrm{X})$ is a cranial nerve with both sensory and motor components and exits through the jugular foramen. Glossopharyngeal general sensory cell bodies are located at the superior ganglion. The visceral sensory and special cell bodies are located at the inferior ganglion and these synapse at the nuclei of solitary tract. Somatic sensory portion has its cell bodies located in the superior ganglion and synapse at the nucleus of trigeminal nerve. The glossopharyngeal nerve is responsible for general sensation from the external ear, posterior third of tongue, tympanic membrane, isthmus of fauces, and pharyngotympanic tube (6). Furthermore, it receives taste sensation from the posterior third of the tongue, chemoreceptor inputs from the carotid body, baroreceptor inputs from the carotid sinuses, and provides parasympathetic innervation to the parotid gland (7).

The glossopharyngeal nerve travels between the internal carotid artery and the internal jugular vein, located deep to the styloid process and the muscles that attach there. It curves around the border of the stylopharyngeus muscle where it continues anteriorly to reach the base of the tongue. The stylohyoid muscle attaches superiorly to the styloid process of the temporal bone and inferiorly to the body of the hyoid bone. It contracts to elevate and retract the hyoid bone in effect elongating the floor of the mouth (7).

\section{The Vagus Nerve}

The vagus nerve $(\mathrm{CN} \mathrm{X}$ ) also exits through the jugular foramen. The cell bodies are contained inside or just outside the jugular foramen in the inferior and superior ganglions. The vagus nerve transmits visceral sensation from the base of tongue, pharynx, larynx, trachea, bronchi, heart, esophagus, stomach, and intestines (6). Additionally, it transmits general sensation from the auricle, external acoustic meatus, and dura mater of the posterior cranial fossa. It leaves the head and neck to deliver parasympathetic fibers to the thoracic and abdominal viscera (7). Because of this broad coverage, many studies have targeted this nerve to treat a multitude of diseases.

\section{Sphenopalatine Ganglion}

The SPG lies in the pterygopalatine fossa and receives sensory, parasympathetic, and sympathetic input. The pterygopalatine fossa lies immediately posterior to the upper jaw or the maxilla and is the location where the maxillary nerve emerges from the cranial cavity. The parasympathetic root comes from the greater petrosal nerve from the facial nerve and the nucleus of origin is the superior salivatory nucleus. The sympathetic system follows the deep petrosal nerve that is a branch of the internal carotid plexus that is a continuation of postsynaptic fibers from the cervical sympathetic trunk. The fibers from superior cervical ganglion pass through the SPG and enter branches of maxillary nerve (6). The SPG has connections to the facial nerve, lesser occipital nerve (LON), and the cutaneous cervical nerves (9). It is stimulated by trigeminal afferents and affects cerebral vascular tone and blood flow. It is a key structure responsible for cranial and facial autonomic symptoms in conditions such as trigeminal neuralgia (TN) and cluster headache $(\mathrm{CH})(10)$.

\section{Otic Ganglion}

The otic ganglion, inferior to the foramen ovale, lies between tensor veli palatini and mandibular nerve. The parasympathetic innervation comes from the tympanic nerve from the glossopharyngeal nerve. The sympathetics are from fibers of the superior cervical ganglion that travel via a plexus on the middle meningeal artery (6). 


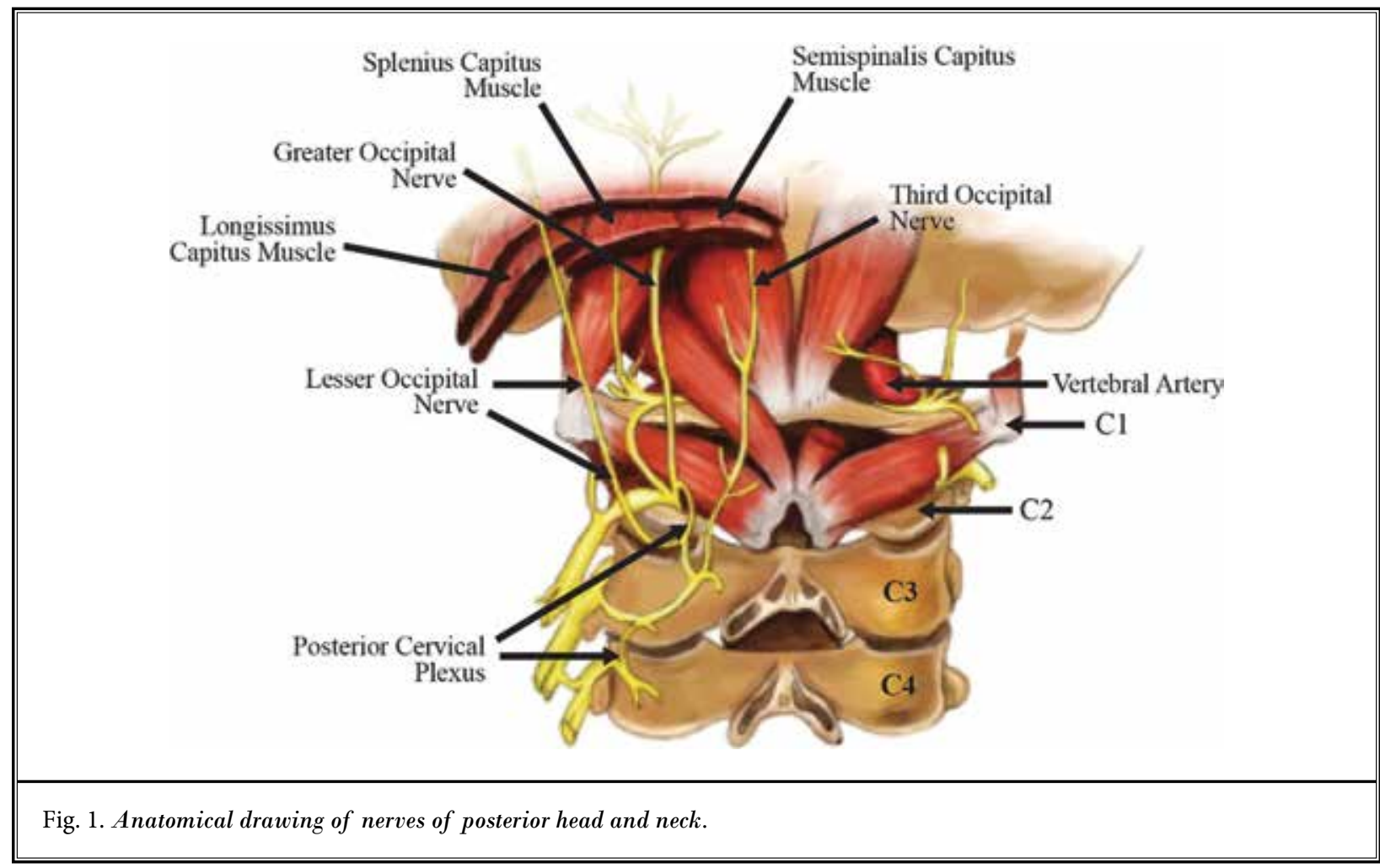

\section{Great Auricular Nerve}

The great auricular nerve is a branch of the cervical plexus (Fig. 1). It arises from the anterior rami of $\mathrm{C} 2$ and C3 spinal nerves, and superiorly follows the sternocleidomastoid muscle where it provides sensory innervation to a small area of the scalp behind the ear (7).

\section{Lesser Occipital Nerve}

The LON, another branch of the cervical plexus, arises from the lateral branch of C2 (sometimes C3) and provides sensation to a more inferior portion of the occiput (11). It provides innervation to an area posterior and superior to the ear (7).

\section{Greater Occipital Nerve}

The greater occipital nerve (GON) branches from the posterior ramus of the $\mathrm{C} 2$ spinal nerve where it emerges under the obliquus capitis inferior muscle, moves cephalically to the suboccipital triangle until it pierces the semispinalis capitis and the trapezius muscle. Here it spreads out to supply a large portion of the posterior scalp up to the vertex (7).

\section{Third Occipital Nerve}

The third occipital nerve is a branch of the poste- rior ramus of the C3 spinal nerve. It emerges through the semispinalis capitis and the trapezius muscle where it supplies a small portion of the lower scalp in the suboccipital region and the zygapophyseal joint C2-C3 (7).

\section{Trigeminocervical Pain Pathway}

This trigeminal system provides the infrastructure for pain and touch sensation to the face and the motor function of the muscles of mastication. The system goes from the midbrain and medulla, including the mesencephalic nucleus, the main sensory nucleus, a spinal nucleus of $\mathrm{CN} \mathrm{V}$, and the motor nucleus. The spinal nucleus of the trigeminal nerve includes the subnucleus oralis, the subnucleus interpolaris, and the subnucleus caudalis. This subnucleus caudalis acts as the dorsal horn and reaches as far caudally to the second (C2) or third cervical level (C3). It is in the nucleus caudalis that the primary afferent synapses and where the second order neuron crosses to form the contralateral spinothalamic tract. It is postulated that activation of nuclei near the trigeminocervical complex may explain the symptoms of aura and other associations common with certain types of headaches (12). Several studies have demonstrated this network connection (Fig. 2) and describe a trigeminocervical pain pathway where activation of 
Fig. 2. Depiction of trigeminocervical complex.

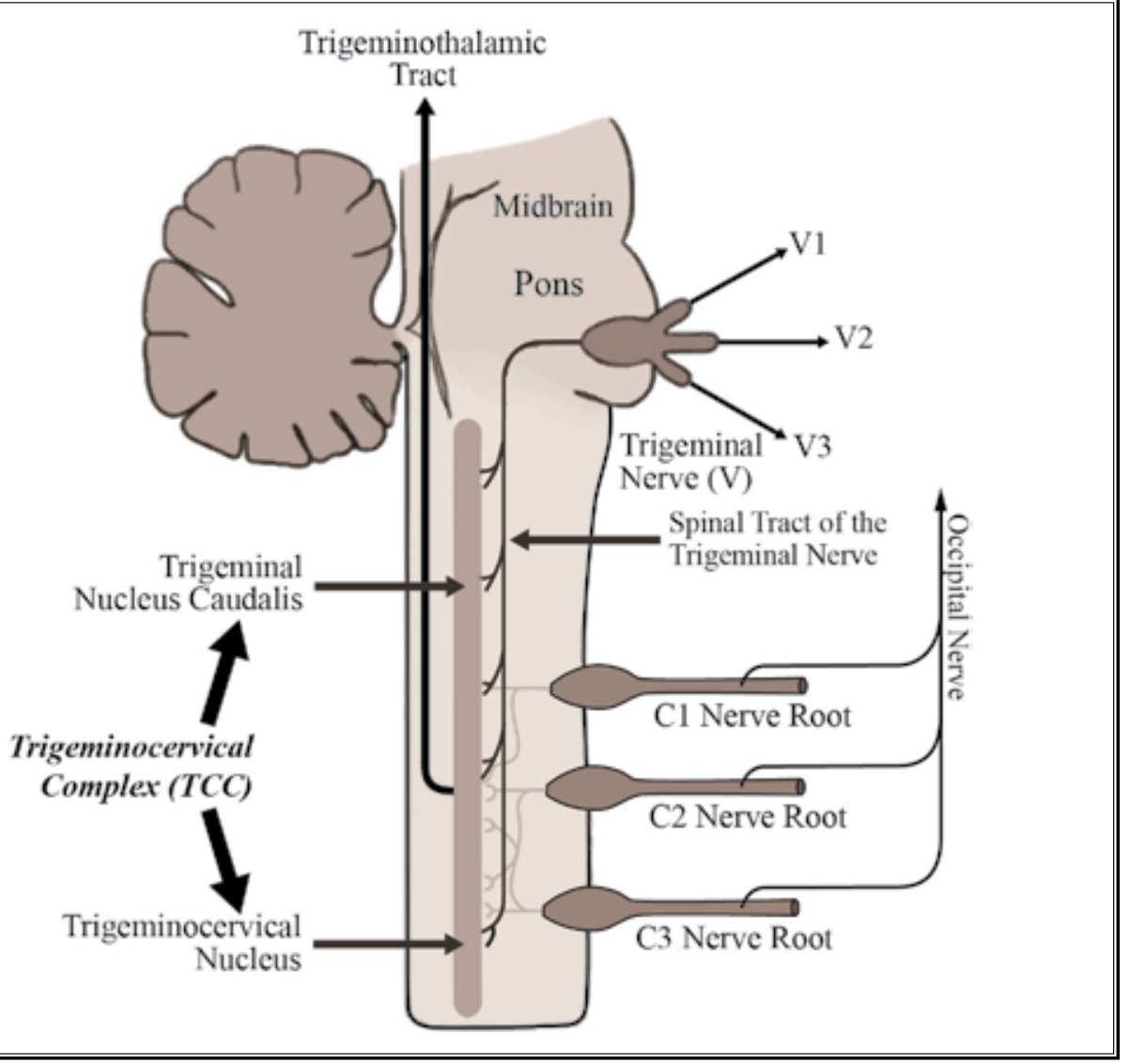

one part of the system leads to a response in other areas (13). Activation of the superior sagittal sinus has the ability to activate from the trigeminal nucleus caudalis to $\mathrm{C} 1$ and $\mathrm{C} 2$ of the dorsal horn. Through stimulation of the GON, metabolic activity increases in the dorsal horn at $C 1$ and C2, and the trigeminal nucleus caudalis (14). Matharu et al (15) analyzed positron emission tomography of 8 patients with chronic migraine (CM) who all responded to implanted bilateral suboccipital stimulators. This functional brain imaging demonstrated thalamic activation response to occipital nerve stimulation (ONS). Therefore because of this connectivity, there are additional interconnected sites that may be targeted. The complex anatomic structures involved in facial pain make assessment and diagnosis difficult, but also offer many potential targets for therapeutic intervention.

\section{Types Of Facial Pain}

\section{Migraine}

Migraine headaches are a common disorder that affects 36 million individuals in the United States alone (16). A study of the global burden of disease in 2015 placed migraine as number 7 of the leading causes of years lived with disability (17). Recently, a one year prevalence of migraines was estimated to be as high as $11.7 \%$ to $13.2 \%$ in the United States (18). The most affected range from age 25 to 55 years with a predominance of women (19). Classically, migraines are described as pulsating pain to one side of the face lasting from a few hours to a few days that may or may not include nausea, vomiting, changes in vision or hearing. These headaches usually occur above the canthomeatal line in a frontotemporal distribution and last from 4 to 72 hours. Children and adolescents are likely to have bilateral headaches that become unilateral by age 18 years. A small portion of women, $<10 \%$, may have migraines associated with their menstrual cycle. Based on the characteristics of the headache, migraines can be further classified into different subtypes that includes migraine with aura, migraine without aura, abdominal migraine, retinal migraine, episodic migraine, and CM, among others. They can be debilitating, as many who suffer from this condition 
require bed rest that detracts from social and occupational function (20).

Prophylactic treatments include beta blockers, tricyclic antidepressants, calcium channel blockers, and anticonvulsants. Triptan drugs and nonsteroidal anti-inflammatory medications remain the most common options for acute symptomatic treatment (17). Approximately $14 \%$ of those with episodic migraine treated at a specialized headache center progressed to $\mathrm{CM}$ regardless of medication usage. Some studies have suggested that medication overuse can actually predispose one to chronicity (21). Refractory CMs has been shown to respond well to peripheral stimulation of the occipital nerve (22).

\section{Cluster Headache}

$\mathrm{CH}$ presents as severe unilateral periorbital pain lasting 15 minutes to several hours that is associated with autonomic symptoms of the face, eyes, and nose. Thus it falls under the grouping of trigeminal autonomic cephalalgias. The attacks tend to follow a circadian pattern in which they often occur at the same time of day, and there is a propensity for nocturnal attacks. $\mathrm{CH}$ lifetime incidence is believed to be approximately 50 cases per 100,000, with 3 times as many men affected than women. First-degree relatives are 14 to 48 times more likely to have $\mathrm{CH}$ than the general population (23). It usually affects individuals between age 20 and 40 years (24). Generally, attacks occur in a group of series that can last for weeks or months separated by months or years of remission, categorized into episodic $\mathrm{CHs}$, in which attacks occur in series lasting from 7 days to 1 year, and chronic $\mathrm{CH}$ in which attacks last for 1 year or longer with remission periods $<3$ months (20).

Abortive treatment includes oxygen and serotonin antagonists. Verapamil is the first-line prophylactic agent but other medications such as steroids, topiramate, and ergotamine have been employed (25). Overall, $15 \%$ to $20 \%$ of patients with chronic $\mathrm{CH}$ do not effectively respond to pharmacologic monotherapy. Refractory chronic $\mathrm{CH}$ has also been shown to respond to supraorbital nerve and SPG stimulation (4).

\section{Occipital Neuralgia}

Occipital neuralgia is a condition characterized by sharp, stabbing pain in the occiput that is often accompanied by allodynia and occipital tenderness (26). General population incidence has been suggested to be 3.2 per 100,000 per year. Chronically contracted muscles and spondylosis of the upper cervical spine have been correlated with irritation of either the GON or LON (27). Common presentation is with shooting, sharp severe pain that recurs lasting from a few seconds to minutes (20). Pain is most commonly unilateral and found in the distribution of the GON. Often idiopathic, other mechanisms such as posttraumatic or even whiplash-induced nerve damage have been proposed.

Medical treatments include anti-inflammatory medications, neuropathic pain medications, and antiepileptic drugs. Occipital nerve blocks and pulsed radiofrequency (PRF) lesioning of both the greater occipital and LONs have been employed (26). The Neuromodulation Appropriateness Consensus Committee concluded that occipital stimulation for occipital neuralgia was a recommendable treatment modality in conditions refractory to conservative medical modalities (4).

\section{Burning Mouth Syndrome}

Burning mouth syndrome (BMS) has been used to describe idiopathic chronic oral mucosal pain. It generally involves burning or itching of the oral mucosa, which is sometimes accompanied by xerostomia and dysgeusia (28). BMS is most frequently reported in perimenopausal or postmenopausal women (12\%-18\%), although the general population prevalence varies on average from $1.0 \%$ to $3.9 \%$, with one review suggesting as low as $0.01 \%$ (29) Those affected most commonly range from age 50 to 60 years (30). Patients commonly present with a daily intraoral superficial burning sensation that lasts at least 2 hours per day for $>3$ months, without any evidence of lesions or pathology of oral mucosa. Pain often fluctuates in strength and is bilateral with predominance to the tip of the tongue (20). The etiology appears to be multifactorial, and although the pathophysiology is not clearly understood, current literature supports involvement of peripheral and central neuropathic pathways, whereas other theories involve mast cell activation and vitamin B12 deficiencies (31-33).

Currently treatment consists of a multidisciplinary approach consisting of stabilizing underlying medical conditions, supportive therapies, and behavioral feedback (34). These modalities have been largely unsatisfactory. A Cochrane review by McMillan et al (35) analyzed current treatment modalities such as antidepressants and antipsychotics, anticonvulsants, benzodiazepines, cholinergics, dietary supplements, electromagnetic radiation, physical barriers, psychological therapies, and topical treatments. They concluded that there is insufficient evidence to support 
or refute the use of any interventions in managing BMS. A review by Rodríguez-de Rivera-Campillo et al (36) concluded that partial improvements could be seen in approximately $60 \%$ of patients if one of their treatments included topical clonazepam. However, the majority of patients respond with partial to no relief and often find themselves constantly trialing multiple medications in attempt to alleviate their symptoms. A blind, placebo-controlled randomized trial treated 12 patients suffering from BMS with prefrontal repetitive transcranial magnetic stimulation. Umezaki et al (37) concluded that there was a significant pain reduction after one week of treatment compared with the placebo control group. Seven patients in the treatment group and 5 in the sham reported mild headaches that disappeared after 1 or 2 days. Based on our literature review, there is no evidence to support that peripheral neuromodulation can be an effective treatment modality for patients with BMS.

\section{Trigeminal Neuralgia}

TN is a condition that causes unilateral, paroxysmal, facial pain. It is mediated by a branch of the trigeminal nerve. Although rare in the general population, TN incidence progresses with age, affecting 2 to 5 per 100,000 per year in the general population and increasing up to 25 per 100,000 per year in people aged > 70 years (38). Women are 1.5 to 1.75 times more likely to be affected. Trigeminal neuropathy has been seen in higher rates in those diagnosed with arterial hypertension, multiple sclerosis, Charcot-Marie-Tooth neuropathy, and glossopharyngeal neuralgia (38). The nature of pain is commonly severe electric shock, stabbing pain lasting from < 1 second to 2 minutes. Pain can follow from an innocuous stimulus at the trigeminal nerve distribution (20).

First-line treatment usually is carbamazepine with additional neuropathic pain agents added as needed. Carbamazepine and oxcarbazepine are first-line treatments and have great efficacy in patients with paroxysmal pain; however, these medications often lead to side effects that lead to a reduction in use by $27 \%$ and $18 \%$ of responding patients, respectively (39). Further invasive therapy can be undertaken with trigeminal nerve blocks, chemical or radiofrequency denervation, and even intracranial microvascular decompression (40).

Another similar condition includes painful trigeminal neuropathy that is defined as pain in one or more branches of the trigeminal nerve caused by another disorder with likely neural damage. This pain is often nearcontinuous and described as burning or squeezing. In comparison to TN, there are less brief pain paroxysms. $\mathrm{PHN}$ is commonly seen in the trigeminal nerve distribution. It is more common in the elderly than younger individuals, and most commonly affects the ophthalmic division when causing facial pain. It can be treated with tricyclic antidepressants or anticonvulsants. Neurolytic treatments are not recommended because of the risk of deafferentation pain (41). Although the Neuromodulation Appropriateness Consensus Committee has not recommended the use of peripheral nerve stimulation (PNS) for trigeminal face pain (4), it may warrant consideration when intractable facial pain or headache can be localized to a specific nerve distribution.

\section{Glossopharyngeal Neuralgia}

Glossopharyngeal neuralgia is a rare condition associated with paroxysmal pain in the distribution of the glossopharyngeal and vagus nerve. Studies have shown an incidence of 0.9 per 100,000 per year in men and 0.5 per 100,000 per year in women, with a mean age of onset of around age 64 years. Although rarer than TN, glossopharyngeal neuralgia has also been associated with multiple sclerosis (38). Based on International Headache Society classification, the condition involves stabbing pain in the ear, base of tongue, tonsillar region, or the angle of the jaw (42). Symptoms can also involve an autonomic component with bradycardia and syncopal episodes (43). Pain of a sharp, electrical nature commonly lasts from a few seconds to minutes. Swallowing, talking, coughing, or yawning often exacerbates this severe pain (20). Causes can be primary and idiopathic or secondary due to compressive lesions such as tumors, soft tissue and bone, or vascular structures (42). Neurovascular compression of the glossopharyngeal nerve may be diagnosed on imaging (20).

Medical treatment involves anticonvulsants, membrane stabilizers, and antidepressants for neuropathic pain. Nerve blocks can be performed at various branches of glossopharyngeal nerve or vagus nerve, however, their efficacy has been questioned. A randomized, prospective, active-controlled, parallel group study showed similar efficacy in treatment between 15 patients with glossopharyngeal neuralgia treated with standard oral therapy of gabapentin, tramadol, and methylcobalamin and the intervention group that received the same oral therapy with additional extraoral glossopharyngeal nerve blocks. Each patient received a diagnostic block with lidocaine followed by alternating day steroid plus bupivacaine for 3 injections and followed by 2 more blocks of only 
bupivacaine. This study lacked image guidance to confirm ideal target of injectate. Although nerve blocks did not appear to add benefit, there were no adverse events, and in refractory cases nerve blocks should still be considered (44).

Surgical treatment involves rhizotomy or nerve section, or microvascular decompression of the glossopharyngeal or vagus nerve (45). A meta-analysis by Lu et al (46) of 792 patients with glossopharyngeal neuralgia treated surgically either by nerve section $(36 \%)$, microvascular decompression $(56 \%)$, or stereotactic radiosurgery $(8 \%)$ concluded a complete long-term (median 33, 56, and 45 months, respectively) pain relief in $91 \%$ overall $(96 \%, 90 \%$, and $82 \%$, respectively). Other studies show surgical treatment has great efficacy; however, temporary nerve deficits can be seen in 20 to $34 \%$ of patients with permanent damage in up to $17 \%$. Recently, Gamma Knife radiosurgery has been proposed as a less invasive option. In one case series, 8 of 9 patients underwent a total of 10 Gamma Knife radiosurgeries targeting the glossopharyngeal meatus of the jugular foramen. A total of 8 patients reported pain relief, with 6 patients pain-free at 3 months and at 46 months on average long-term follow-up (47). Currently, there is no literature to support management of this condition with neurostimulation.

\section{Eagle's Syndrome}

Eagle's syndrome is a condition with 2 subtypes causing orofacial pain (48). Usually after a tonsillectomy, "classic type" presents with a foreign body sensation in the throat, dysphagia, frequent swallowing, and pain referred to the ear and TMJ region. Dr. Eagle hypothesized that this was due to scar tissue compressing and stretching nerve structures around the styloid process (49). "Carotid type" Eagle's syndrome occurs when an elongated styloid process impinges on the carotid artery. This can involve either the external carotid only or the internal carotid as well. Symptoms are usually exacerbated by turning the head toward the affected side (49). Some $4 \%$ to $7.3 \%$ of the general population are found to have an elongated styloid process and of this small cohort only $4 \%$ to $10.3 \%$ will present with pain. Eagle's syndrome disproportionately affects women and the elderly (50). Several mechanisms have been proposed for the etiology of pain including pressure on surrounding structures, compression of adjacent nerves primarily the glossopharyngeal nerve, lower branch of the trigeminal nerve or chorda tympani, degenerative changes at the tendinous stylohyoid insertion, or irritation of the sympathetic nerves through impingement of the carotid vessels (51). Currently, Eagle's syndrome is defined as unilateral headache that includes neck, pharyngeal, and/or facial pain that is the result of inflammation of the stylohyoid ligament. Because of the mechanical nature of injury, pain is often instigated by palpation of the stylohyoid ligament or by head turning (20). Usual treatments range from conservative management with systemic analgesics, to local steroid infiltration, and even surgical intervention (50). Although successful management of Eagle's syndrome with PRF treatment has been reported (52), there remains little data to support management of this condition with neurostimulation. Styloidectomy is considered the treatment of choice (53).

\section{Paroxysmal Hemicrania}

Paroxysmal hemicrania $(\mathrm{PH})$ is a trigeminal autonomic cephalgia that is both underreported and underdiagnosed according to a recent review (54). Prevalence is suggested to be approximately 2 to 20 per 100,000 . Age of onset is generally 30 to 40 years, affecting both men and women equally. Some $10 \%$ of cases display a clear trigger mechanism with the most common being neck movement. Only approximately $20 \%$ of $\mathrm{PH}$ behave episodically, and many of these ultimately end up developing into a chronic form in which attacks occur for $>1$ year with remission periods of $<3$ months in between (23). Patients commonly present with 5 to 40 attacks per day lasting 2 to 30 minutes each (20). It most commonly affects the temporal region in a unilateral fashion and is associated with typical cranial autonomic symptoms, such as lacrimation, conjunctival injection, or rhinorrhea. The occipital region may be involved in up to $40 \%$ of cases. Neck and shoulder pain may be present in up to onethird of cases (55). A distinguishing feature of $\mathrm{PH}$ is resolution of symptoms with indomethacin. However, a subset of patients has been identified in which symptoms are severe and do not respond to indomethacin or other pharmacologic interventions (54). One case report using a sphenopalatine endoscopic ganglion block with local anesthetic and steroid demonstrated significant frequency and pain relief in a patient who was unresponsive to conservative treatment (56). In these refractory cases, transcutaneous stimulation of the vagal nerve (57) and neuromodulation of the GON or SPG may be an option (54). 


\section{Conventional Treatment For Craniofacial PaIN}

Numerous treatments have been described for craniofacial pain. Although many have the potential for excellent outcomes, a substantial number of patients regularly cycle through treatments never achieving permanent success. Often headaches are sparked from certain known triggers; the first steps are to avoid these stimuli. Patients should limit caffeine, nitrates, alcohol, monosodium glutamate, aspartame, stressful situations, poor sleep hygiene, dehydration, and bright lights (58). When pain continues despite these methods, medical treatment is indicated.

\section{Pain Medication}

Traditionally oral medications are first-line treatment because of their ease of use and relatively adequate risk profile. For general neuropathic pain, first-line drugs include tricyclic antidepressants, for example amitriptyline, serotonin-norepinephrine reuptake inhibitors such as duloxetine or venlafaxine, and anticonvulsants such as gabapentin or pregabalin. Medications with a weaker grade of recommendation include oral tramadol, capsaicin patches, and lidocaine patches. Patients regularly find themselves on multiple medication regimens and often trialing new classes as relief is unsatisfactory. However, there are some conditions that have shown positive outcomes with specific medications. For instance, the anticonvulsant carbamazepine has displayed positive efficacy in TN (59). In addition, the nonsteroidal anti-inflammatory drug (NSAID) indomethacin has excellent efficacy in patients with PH (54).

Regarding headaches, treatment often focuses on either abortive or prophylactic therapy. Abortive medications are taken after a migraine attack has already commenced, whereas prophylactic treatments are designed to either minimize the intensity or frequency of the regularly experienced headaches. Abortive treatments include triptans and other 5-hydroxytyptamine agonists that have vasoconstricting properties. Oxygen therapy is often used when accessible in settings of acute attacks. Butalbital can be combined with caffeine and acetaminophen or aspirin. NSAIDs may have effectiveness in mild to moderate migraine pain. A short course of steroids can also provide relief. Overall, narcotics should be avoided whenever possible. For prophylactic treatment, beta-blockers are frequently used and have shown good efficacy. Anticonvulsants, antidepressants, and antihypertensives, such as candesartan or lisino- pril, have been commonly trialed. Studies have shown that taking these medications > 10 times per month over a prolonged period of time can lead to negative consequences from the medications themselves, or worsening of headaches through rebound headache syndrome. Furthermore, these medications often have a delayed onset that limits their action in acute attacks. Because of this lag time, many treatments have focused on preventing the number of attacks (58).

\section{Physical Therapy}

Similar to most chronic pain syndromes, physical therapy (PT) can offer therapeutic benefit. PT has been mostly studied in migraine patients and has been shown to increase the patient's perception of change and overall satisfaction to migraine treatment. PT has been demonstrated to reduce nociceptive afferents in the craniocervical region (60). Although there remains limited evidence suggesting PT or aerobic exercise improves frequency or duration of headaches, PT remains a useful tool with minimal risk and possible improvement in overall pain intensity (61).

\section{Psychological Treatment}

A holistic approach often includes behavioral therapy. Biofeedback has shown positive outcomes in treating tension and migraine headaches. Biofeedback allows the patient to be informed on the physiologic process that is occurring, bringing the patient new awareness on their condition. In theory, the patient will be able to use this knowledge to learn how to voluntary control the previously involuntary processes of pain. Feedback is often provided through electromyography in various muscles or through topical temperature readings (62).

Cognitive-behavioral therapy takes advantage of the link between emotional factors and pain. Therapy usually includes relaxation training, operant conditioning, and focusing on specific attitudes and beliefs that may trigger behavioral or emotional pain responses. Social support groups have proven to be beneficial in patients with chronic pain, including migraine (62).

\section{Acupuncture}

Acupuncture has been trialed in areas of the head and face. For TN, acupuncture has shown to reduce severity of attacks (63). In addition, several studies have concluded that acupuncture treatment may be beneficial when compared with current prophylactic drug therapy in preventing and treating both migraine and tension headache (64). 


\section{Trigger Point Injection}

Although common in clinical practice, there is little data on the efficacy of trigger point injections for treatment of craniofacial pain. There is no defined optimal drug regimen or injection schedule (65). In patients with tight or tender muscles, routine trigger point injections may provide some symptomatic relief.

\section{Botulinum Toxin Injection}

Injections with onabotulinumtoxinA in the pericranial muscles has been approved for $\mathrm{CM}$ headaches since 2010 by the US Food and Drug Administration. Diener et al (66) described the technique of 31 separate fixed-site intramuscular injections each delivering 5 units of onabotulinumtoxinA for a total dose of 155 units. The injections were divided over 7 defined head and neck muscle areas: corrugator, procerus, frontalis, temporalis, occipitalis, cervical paraspinal and trapezius. Depending on the patient's symptoms, an additional 40 units may have been given to the occipitalis, temporalis, and/or trapezius muscle groups. After 2 cycles separated by 12 weeks, there were positive outcomes including reduction in disability and improvement in function, vitality, and quality of life. The authors conclude onabotulinumtoxinA is effective for prophylaxis of headache in adults with $\mathrm{CM}$. A recent review of guidelines reports onabotulinumtoxinA is safe and effective for reducing the number of headache days in patients with $\mathrm{CM}$, but is ineffective for patients with episodic migraine and is probably ineffective for treating chronic tension-type headaches (67). In addition, botulinum toxin has been trialed for facial nerve pain and spasms, such as in TN, however, larger studies are required (58).

\section{Nerve Block}

Local anesthetic and steroid injections are often used to target specific nerves. These treatments often have short-lasting responses and require frequent repeat injections. At times, relief may last from weeks to months because of a response in central pain modulation. Common targets include the GON, LON, and trigeminal nerve including its supratrochlear, supraorbital, and auriculotemporal branches. These procedures can be performed using anatomic landmarks or image guidance including fluoroscopy or ultrasound. Although there are few well-controlled trials, the greatest evidence is for greater occipital blocks in patients with $\mathrm{CH}$ (68). Furthermore, temporary nerve blocks can aid in establishing the diagnosis.

\section{SPG Block}

The SPG has been specifically targeted as it contributes to the autonomic response displayed by many craniofacial pain syndromes (69). There is moderate evidence for the use of SPG blockage to treat $\mathrm{CH}$ s with cocaine or the preferred lidocaine. The addition of steroids may extend relief, however, evidence is weak. For migraines, one study demonstrated significant relief lasting 24 hours with bupivacaine application. Similarly, lidocaine nasal spray has been effective to treat TN. Although SPG block has efficacy acutely, there remains a lack of evidence for chronic pain management (70).

\section{Radiofrequency Ablation}

Radiofrequency ablation (RFA) uses heat energy to create tissue destruction and loss of myelinated fibers, thus creating the ability to provide longer pain relief when compared with local anesthetic and steroid blocks. RFA has strong evidence when targeting the SPG when treating intractable CHs (69). Observational cohort studies report short to intermediate pain relief in occipital neuralgia (27). Similarly, in patients with TN, RFA of the Gasserian ganglion has displayed positive outcomes. Of note, longer pain relief was observed in patients with mandibular division pathology compared with those with maxillary branch or multiple distributions of pain (71). PRF works by induction of a low-intensity electrical field around sensory nerves that causes an overall decrease in conduction and an inhibition of long-term activation without associated thermal coagulation seen with standard RFA at higher temperatures. Recently, PRF of the Gasserian ganglion was shown to be an effective, safe and nondestructive method for those patients with intractable TN (72).

\section{Chemical Neurolysis and Chemodenervation}

Neurolysis of any nerve can be achieved through conventional radiofrequency, electromagnetic field PRF, or chemical neurolysis with phenol and alcohol, or more commonly glycerol. Neurolysis of the Gasserian ganglion has been used for $\mathrm{TN}$ and $\mathrm{CHs}$ (73). The most common complication includes facial hypoesthesia for $>$ 2 weeks. Rare complications, from $0 \%$ to $2 \%$, are cranial neuropathies and bacterial meningitis (74). Another option is percutaneous microcompression using a balloon catheter to compress the Gasserian ganglion. Neurolysis of the SPG has shown promise in treating patients with sphenopalatine neuralgia, $\mathrm{TN}, \mathrm{CH}$, migraine, and other atypical facial pain. The SPG is targeted through an infrazygomatic approach (73). 


\section{Intravenous Transfusion}

Intravenous lidocaine has been thoroughly studied in patients with chronic pain. Retrospective cases have demonstrated promise using intravenous lidocaine in chronic daily headache. In patients with PHN, intravenous lidocaine has displayed significant improvements in pain scores. Further studies are indicated for intravenous therapy including lidocaine, ketamine, and phentolamine (75).

\section{Surgery}

Surgery can successfully relieve irritation of a nerve or can provide relief through nerve resection. Microvascular decompression has shown success in patients with TN when a neighboring vessel, usually the superior cerebellar artery, is responsible for compression of the nerve root. If no compressing vessel is identified, internal neurolysis may be performed that divides the nerve into 8 to 10 bundles from the pons to the petrous bone (74). Pain relief can also be achieved through intentional direct injury to or disruption of the offending nerve. In addition to the inherent risk of invasive surgery itself, destruction of a nerve may increase the risk of developing difficult to treat pain conditions such as causalgia or neuroma formation (27).

Another procedure, nucleus caudalis dorsal root entry zone ablation has reported good outcomes in treating refractory TN, atypical headache, and complex craniofacial pain. The trigeminal nucleus caudalis has been described to receive and integrate nociceptive sensation. This procedure is performed under open surgery as the substantia gelatinosa at the nucleus caudalis level is lesioned. Because of the risks of damage to the brainstem during surgical manipulation, this procedure is often a last resort. Another technique, trigeminal tractotomy and nucleotomy involves lesioning the descending spinal trigeminal tracts in the medulla along with the nucleus caudalis. Surgical procedures are reserved for intractable severe cases (74).

\section{Gamma Knife Radiosurgery}

Gamma Knife radiosurgery has been developed for the treatment of nerve pain such as TN. This technique involves radiation of the trigeminal nerve usually 2 to $4 \mathrm{~mm}$ anterior to the brainstem. Studies have shown this technique to have excellent efficacy after a lag period of a few months. This technique is hopeful to provide relief with limited complications (63).

\section{Cranial Targeted Neuromoduatation TECHNIQUES}

\section{Transcranial Direct Current Stimulation}

Transcranial direct current stimulation involves applying weak electrical currents over the scalp. By specifically placing one electrode over a target area, the cranial neuronal firing may be either increased or decreased. A recent review suggests there is low to moderate evidence for transcranial direct current stimulation to promote pain control and reduce pain medication intake in migraineurs (76).

\section{Repetitive Transcranial Magnetic Stimulation}

Repetitive transcranial magnetic stimulation is a form of noninvasive neurostimulation focusing changes in magnetic fields to deep brain targets in hopes of upregulating or downregulating certain neural activity. For pain, the primary targets investigated include the primary motor cortex and the dorsolateral prefrontal cortex. Some success with minimal risk has been reported in patients with migraine and TN, however, efficacy has not proven to be consistent (77).

\section{Deep Brain Stimulation}

Deep brain stimulation involves placing electrical devices intracranially and targeting subcortical regions. Several studies have displayed positive results in patients with chronic pain by targeting deep brain structures including the sensory thalamus, periaqueductal and periventricular gray, and the anterior cingulate cortex. Because of the severity of possible complications, deep brain stimulation is only recommended after exhausting other modalities (78).

\section{LeVELS OF EvidenCE}

When reviewing the available literature, it is crucial to define the overall level of evidence a study provides before the research conclusions can be adopted to clinical practice. A concrete protocol is needed when analyzing studies to create evidence-based guidelines. Manchikanti et al (79) has developed an interventional specific pain management instrument used in assessing the methodologic quality of trials (Table 1). Traditionally, randomized controlled trials (RCTs) are generally considered to be superior evidence than studies without randomization and without controls. The lowest levels of evidence are obtained from observational-based clinical experience or reports of expert committees. Using this qualified modified approach to grading of evidence, we are better able to put the totality of evidence into perspective (79). 
Table 1. Qualified Modified Approach to Grading of Evidence

\begin{tabular}{|c|c|c|c|}
\hline \multicolumn{2}{|c|}{ Qualified Modified Approach to Grading of Evidence (79) } \\
\hline Level I & Strong & $\begin{array}{r}\text { 2 or more relevant high quality RCTs for effectiveness, or 4 or more relevant high quality observational studies or } \\
\text { large case series for assessment of preventive measures, } \\
\text { adverse, consequences, and effectiveness of other measures. }\end{array}$ \\
\hline Level II & Moderate & $\begin{array}{c}\text { At least 1 relevant high quality RCT or multiple relevant moderate or low quality RCTs, or at least 2 high quality } \\
\text { relevant observational studies or large case series for assessment of preventive measures, adverse consequences, } \\
\text { and effectiveness of other measures. }\end{array}$ \\
\hline Level III & Fair & $\begin{array}{c}\text { At least 1 relevant high quality nonrandomized trial or observational study with multiple moderate or low quality } \\
\text { observation studies, or at least one high quality relevant observation study or large case series for assessment of } \\
\text { preventative measures, adverse consequences, effectiveness of other measures. }\end{array}$ \\
\hline Level IV & $\begin{array}{c}\text { Limited } \\
\text { Level V }\end{array}$ & $\begin{array}{c}\text { Multiple moderate or low quality relevant observational studies, or moderate quality observation studies or large } \\
\text { case series for assessment of preventative measures, adverse consequences, and effectiveness of other measures. } \\
\text { based }\end{array}$ & $\begin{array}{c}\text { Opinion or consensus of a large group of clinicians for effectiveness as well as to assess preventive measures, } \\
\text { adverse consequences, effectiveness of other measures, or single case reports. }\end{array}$ \\
\hline \hline
\end{tabular}

\section{Neuromodulation for Headaches and Facial Pain: Evidence and Rationale}

\section{Peripheral Nerve Stimulation}

Although intractable pain of the trunk and/or limbs has been the traditional indication for neuromodulation via spinal cord stimulation (SCS), refractory facial and headache pain has been shown to respond to neurostimulation in some cases. When conservative medical management fails and surgery is not appropriate, has failed, or is contraindicated, neurostimulation can be a viable alternative (4). Various targets and techniques have been employed using neuromodulation for facial and headache pain (Table 2). However, PNS for facial pain and headache is not without risk as stimulation of extracranial nerves may be more technically challenging than stimulation of peripheral nerves in the torso or extremities. Common complications include infection, skin erosion, seroma, allodynia over the lead site, as well as technical complications such as lead migration, lead fracture, and battery malfunction. Although there are not enough data to reliably compare complication rates of extracranial PNS targets, mitigation of adverse events to improve patient safety and outcomes should be of upmost priority. The same principles of appropriate patient selection that apply for traditional SCS apply for this modality. Consensus recommendations also support the consideration of neurostimulation prior to initiation of long-term, long-acting opioid therapy (4).

\section{Trigeminal Nerve Stimulation}

Although central and peripheral techniques of trigeminal nerve stimulation have been well described in literature, PNS has proved to be the safer, more reliable option $(4,80,81)$. Ophthalmic, maxillary, and mandibular branches of the trigeminal nerve, as well as more distal branches such as the supraorbital, infraorbital, and auriculotemporal nerves anatomically lend themselves as good targets for PNS for facial pain (4). In 2004, Johnson et al (82) reported on 10 patients treated with implanted subcutaneous pulse generators and quadripolar electrodes to stimulate the supraorbital or infraorbital branches of the trigeminal nerve. This retrospective analysis showed promising results, as $70 \%$ of patients experienced at least a $50 \%$ degree of pain relief and $70 \%$ reported a decrease in medication use up to 4 years postimplantation. Of note, all 5 patients who were originally diagnosed with posttraumatic neuropathic pain had at least a $50 \%$ pain reduction posttreatment, whereas 2 out of 4 of those diagnosed with postherpetic neuropathy had a therapeutic outcome. The overall complication rate was high at $30 \%$, with 2 patients developing wound breakdown over the connector and another patient with discomfort associated with the tension of the extension lead during head movements, each of these 3 were later successfully managed through repeat surgical intervention.

In 2006, Slavin et al (83) reviewed prospectively collected data of 30 patients who were trialed with PNS of which 22 had permanent stimulation implant surgery for their neuropathic craniofacial pain. The targets included 4 supraorbital, 3 infraorbital, and 13 occipital nerves, with 2 patients having a combination of either infraorbital and occipital or supraorbital and occipital. Twelve patients (10 occipital and 2 supraorbital) had bilateral stimulation. A total of 16 of the 22 patients reported $>50 \%$ pain relief. Specifically, 9 patients underwent implantation for trigeminal neuropathic pain, 


\begin{tabular}{|c|c|c|c|c|c|}
\hline 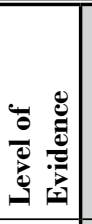 & 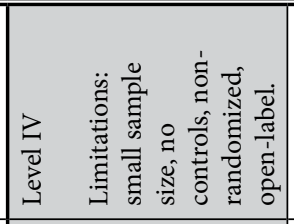 & 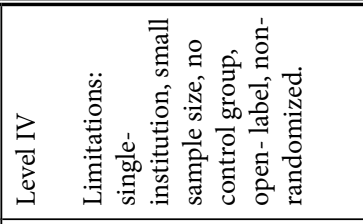 & 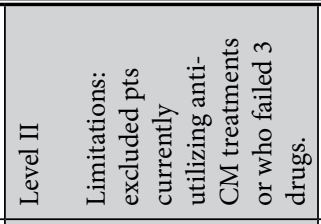 & 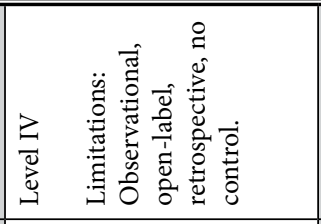 & 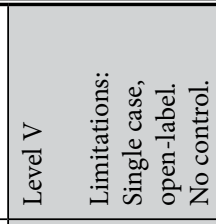 \\
\hline & 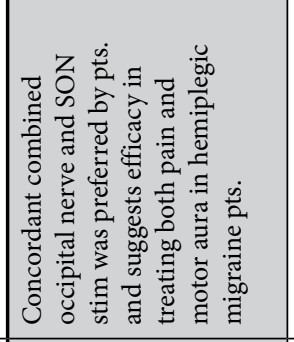 & 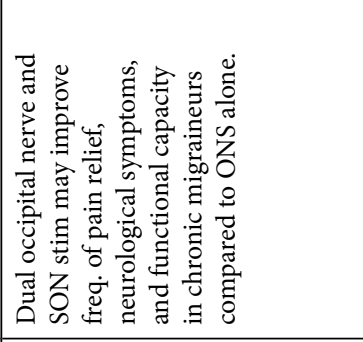 & 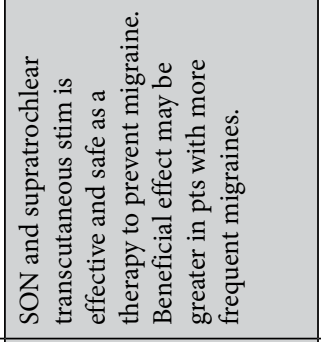 & 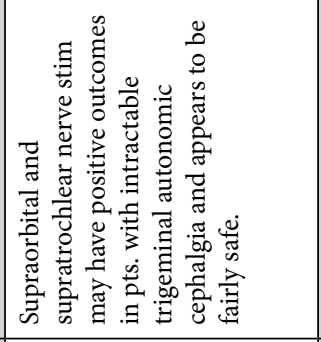 & 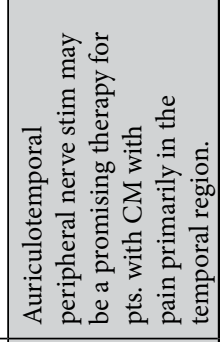 \\
\hline & 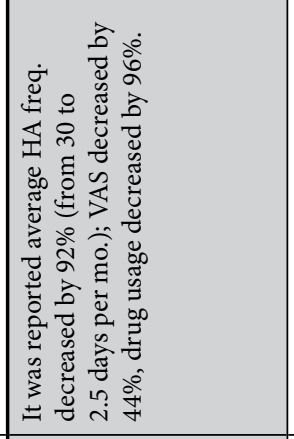 & 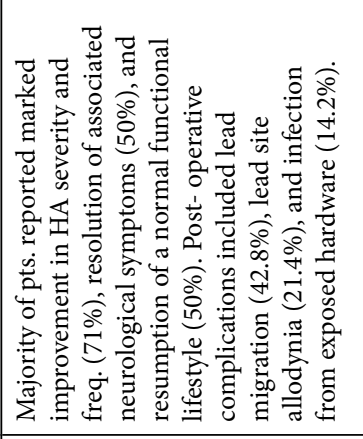 & 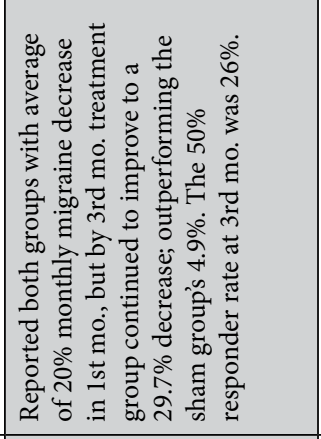 & 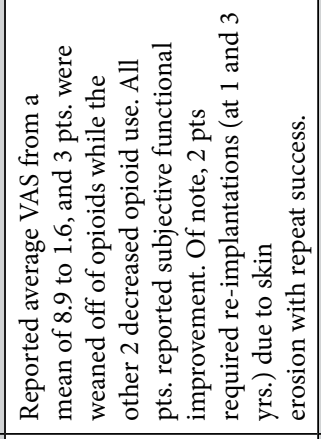 & 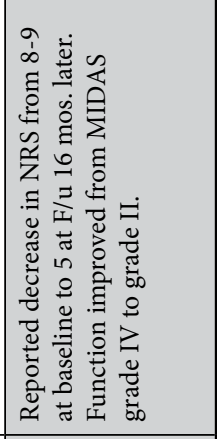 \\
\hline 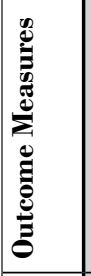 & 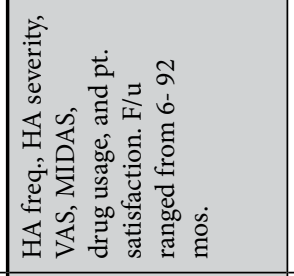 & 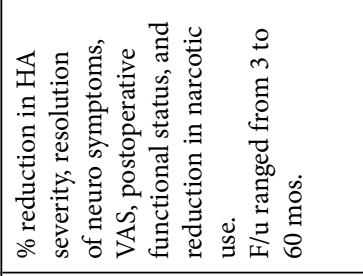 & 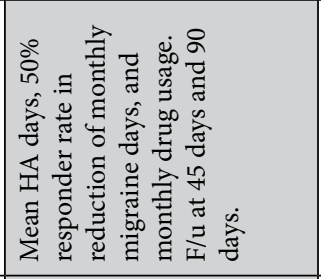 & 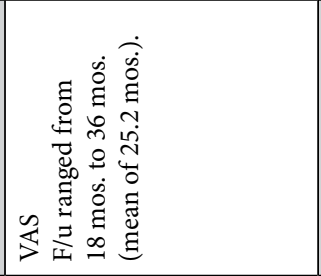 & 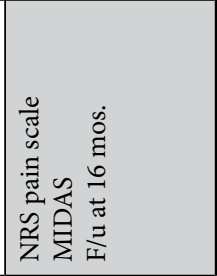 \\
\hline & 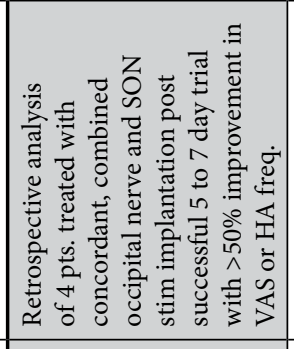 & 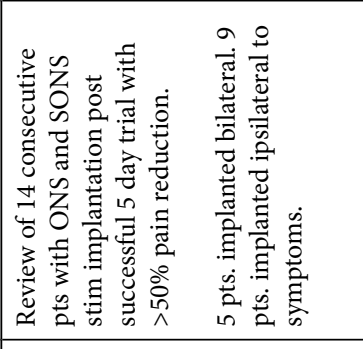 & 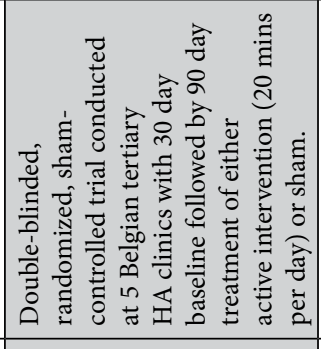 & 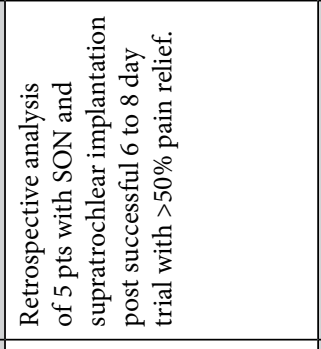 & 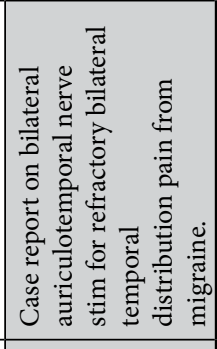 \\
\hline 疍: & 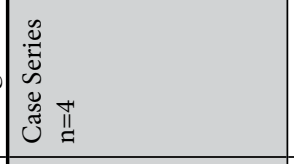 & 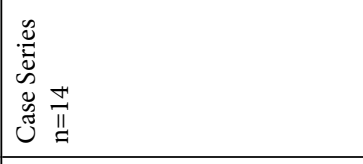 & 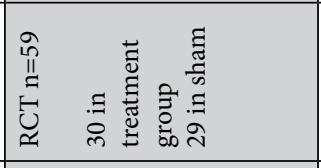 & 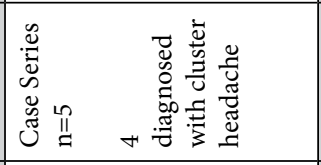 & 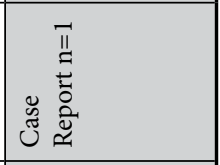 \\
\hline 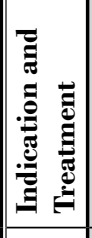 & 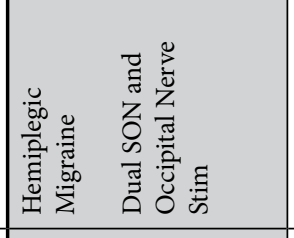 & 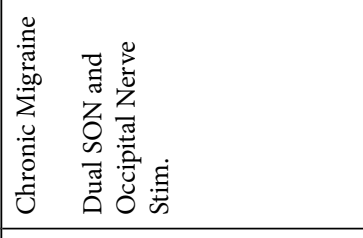 & 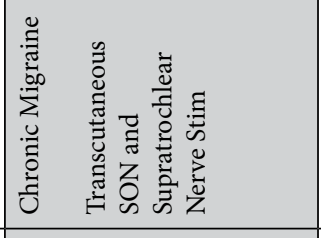 & 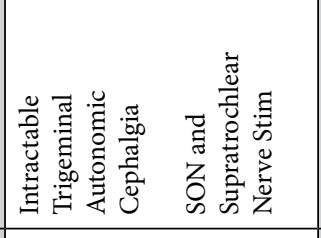 & 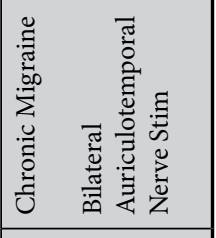 \\
\hline 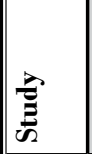 & 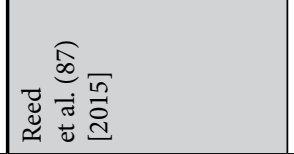 & 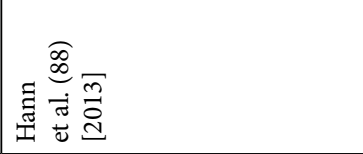 & 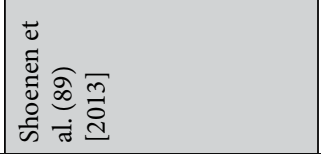 & 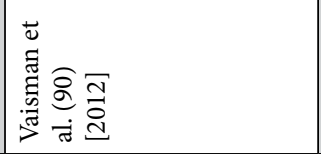 & 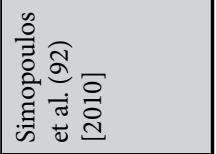 \\
\hline
\end{tabular}




\begin{tabular}{|c|c|c|c|c|c|}
\hline 莺 & 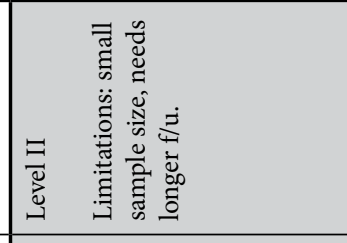 & 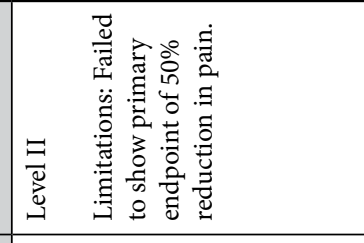 & 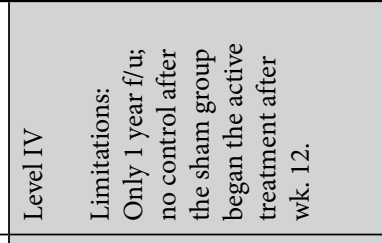 & 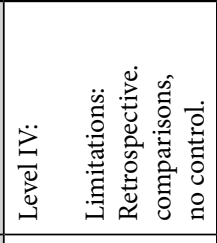 & 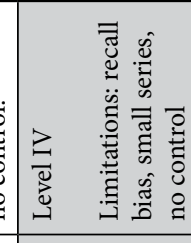 \\
\hline 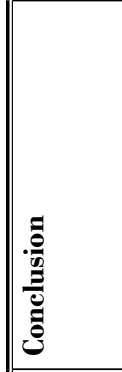 & 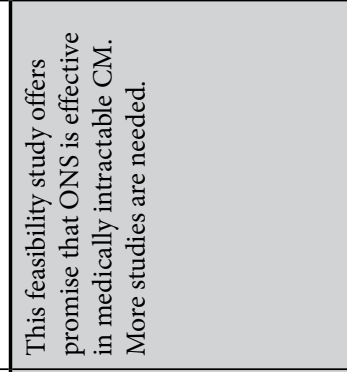 & 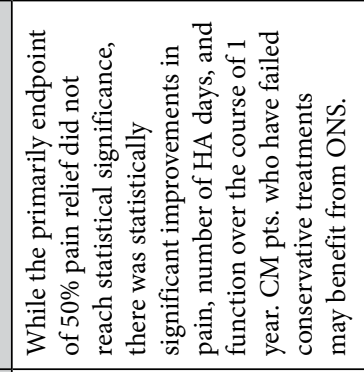 & 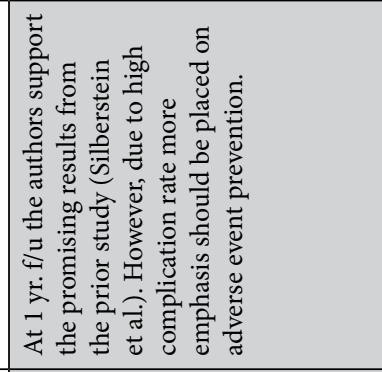 & 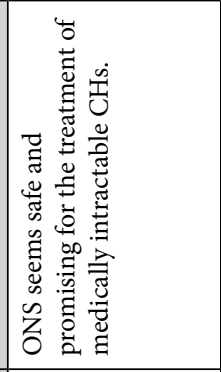 & 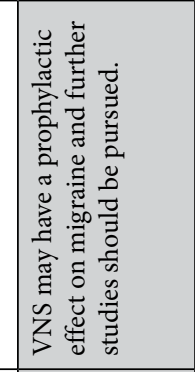 \\
\hline 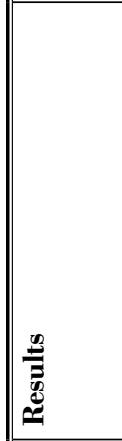 & 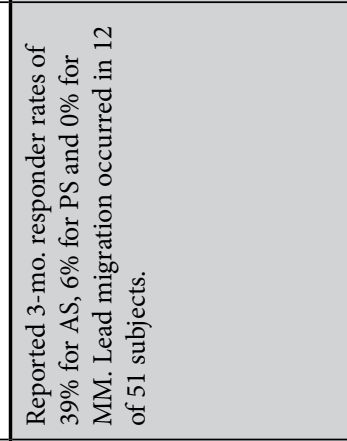 & 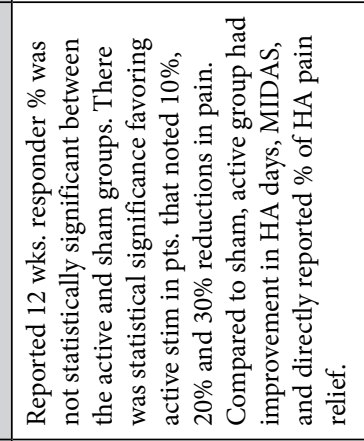 & 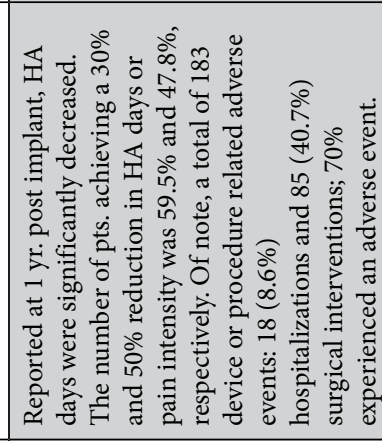 & 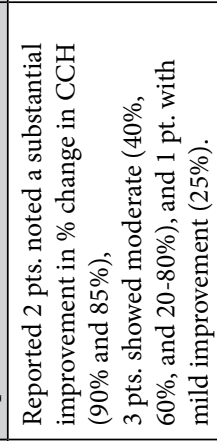 & 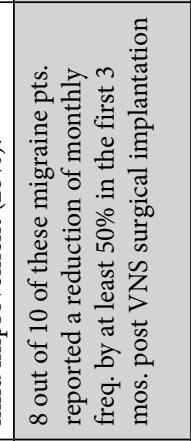 \\
\hline 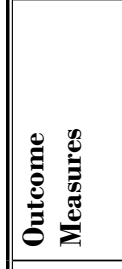 & 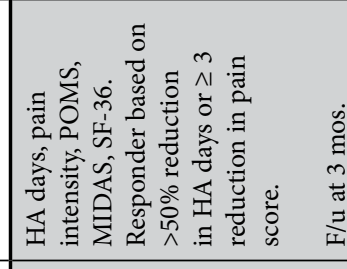 & 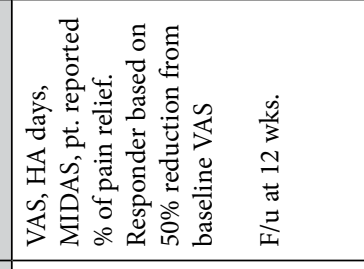 & 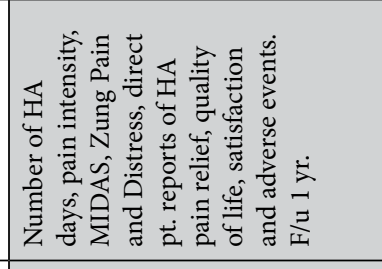 & 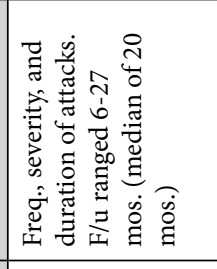 & 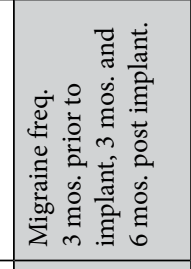 \\
\hline 总 & 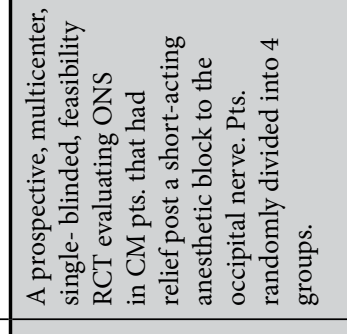 & 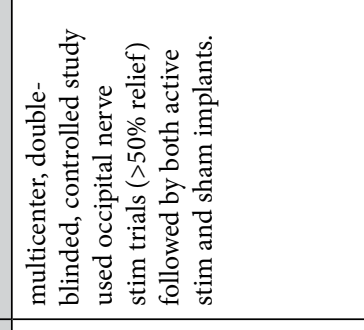 & 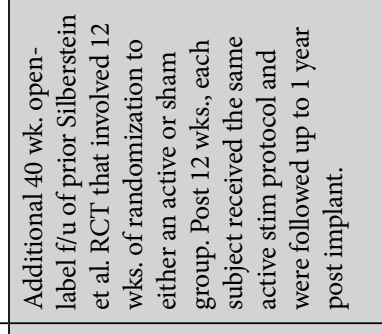 & 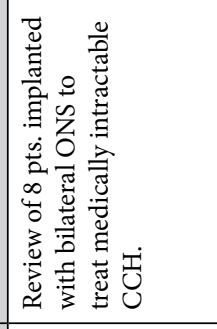 & 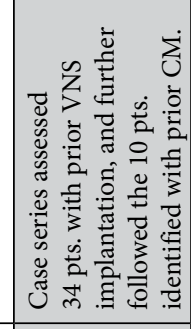 \\
\hline 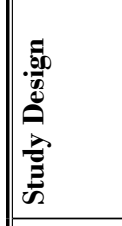 & 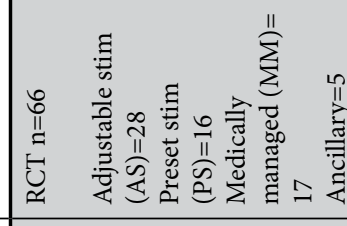 & 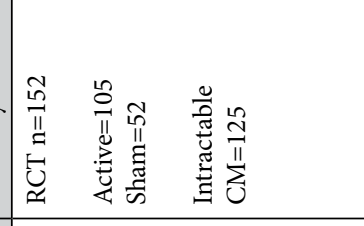 & 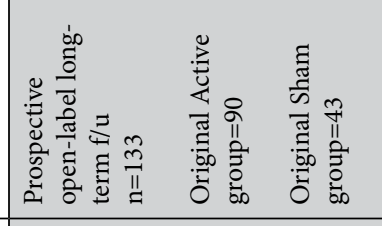 & 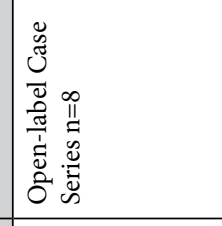 & 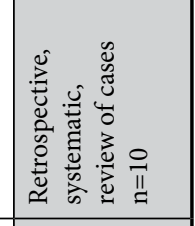 \\
\hline 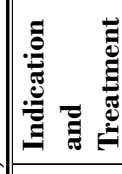 & 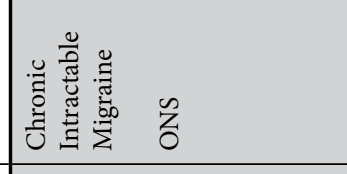 & 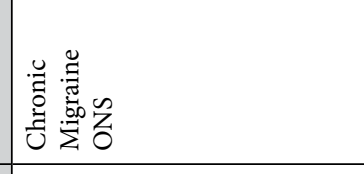 & 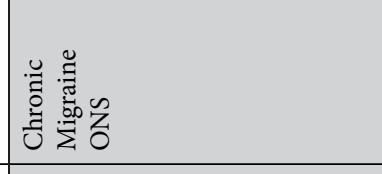 & 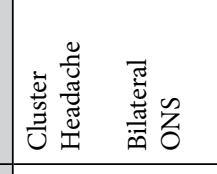 & 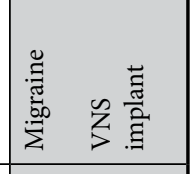 \\
\hline 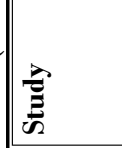 & 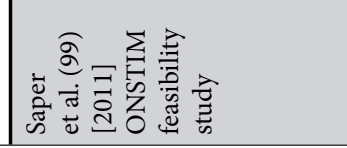 & 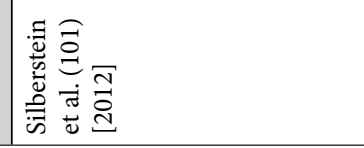 & 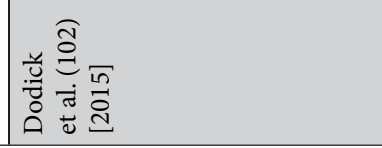 & 㶾 & 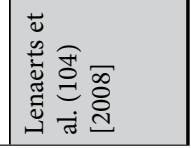 \\
\hline
\end{tabular}




\begin{tabular}{|c|c|c|c|c|c|c|}
\hline 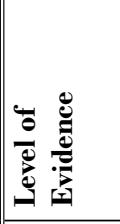 & 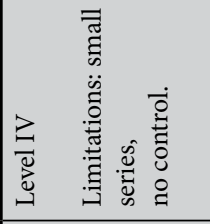 & 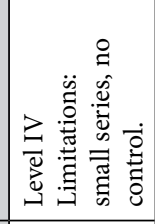 & 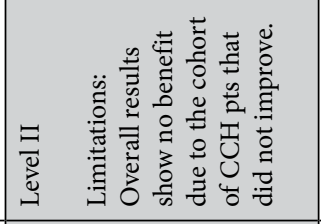 & 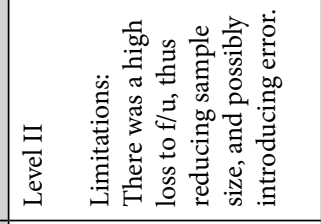 & 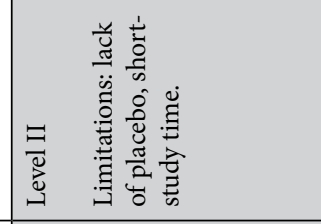 & 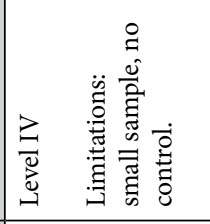 \\
\hline 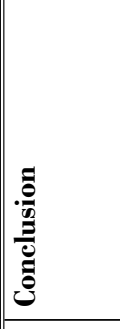 & 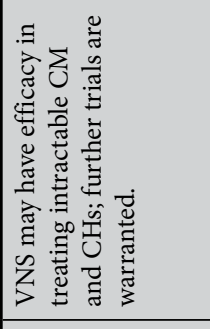 & 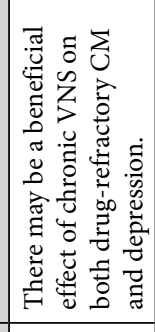 & 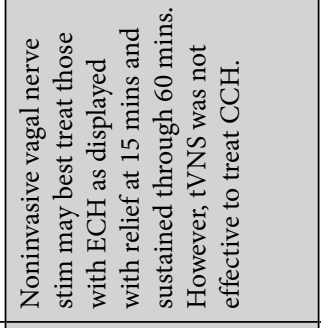 & 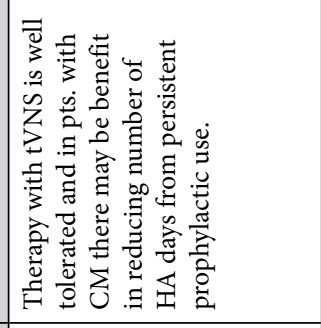 & 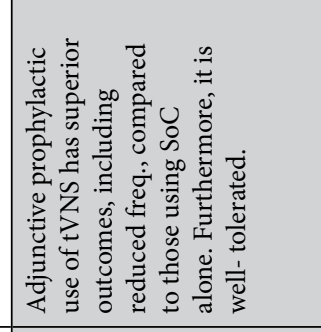 & 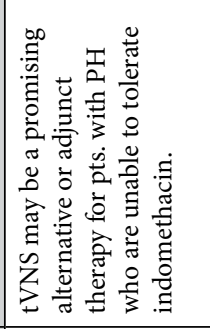 \\
\hline & 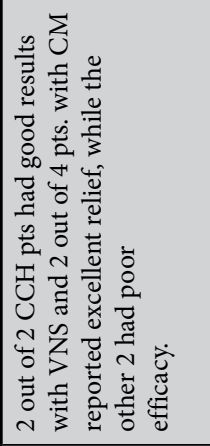 & 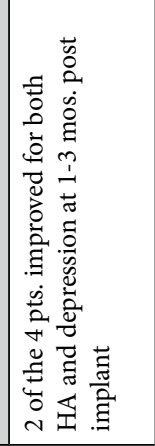 & 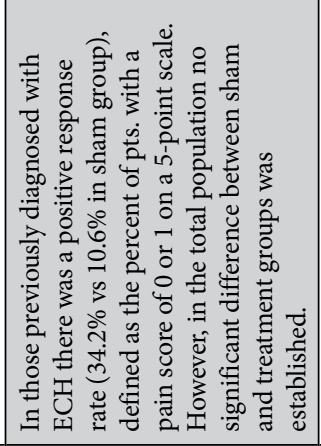 & 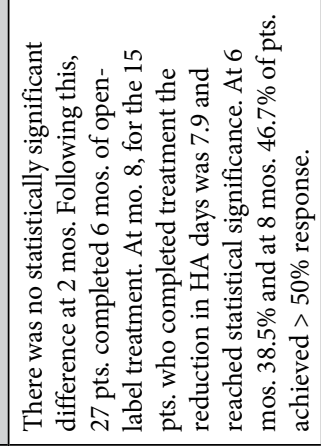 & 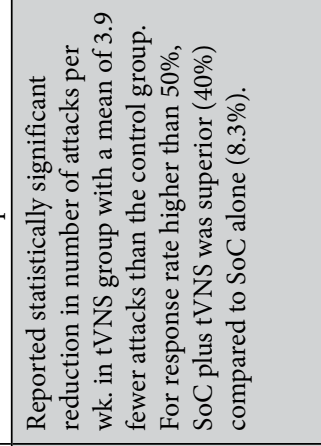 & 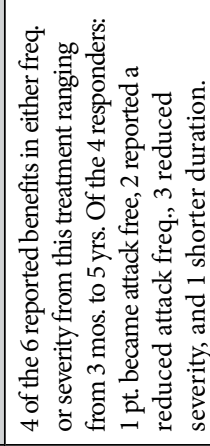 \\
\hline 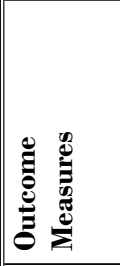 & 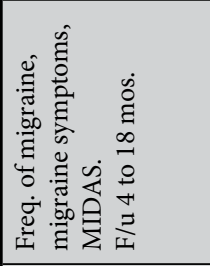 & 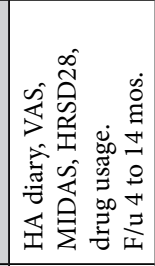 & 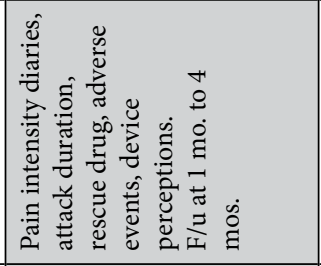 & 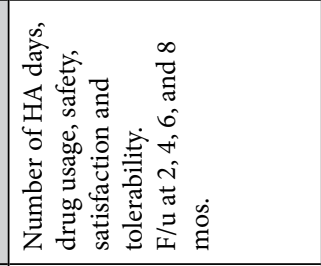 & 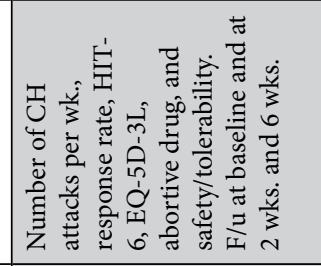 & 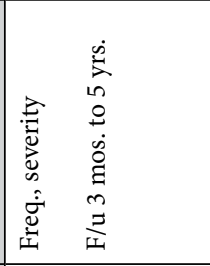 \\
\hline 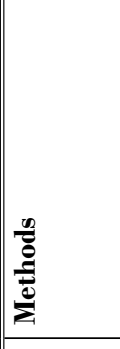 & 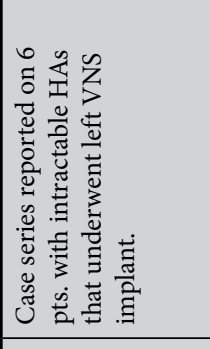 & 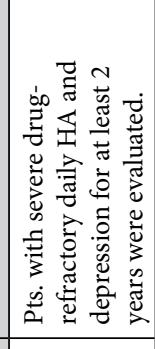 & 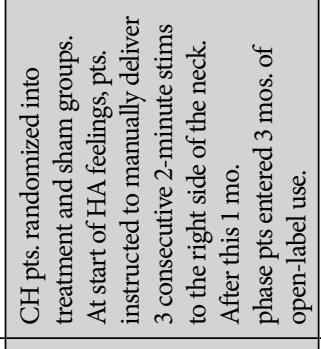 & 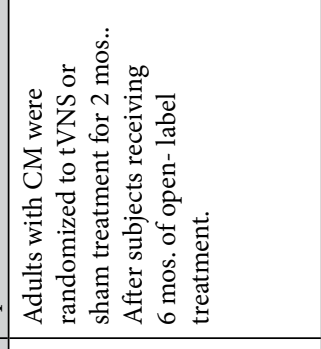 & 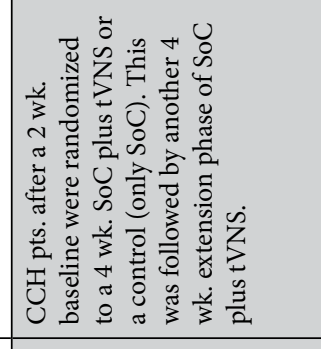 & 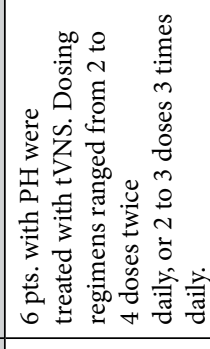 \\
\hline 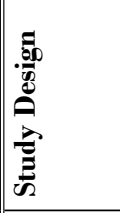 & 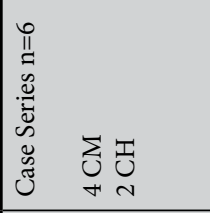 & 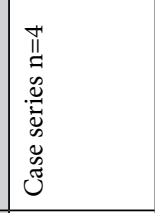 & 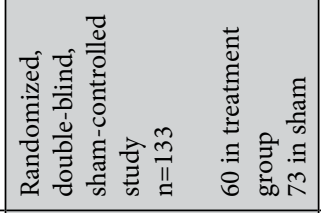 & 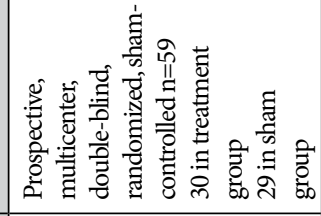 & 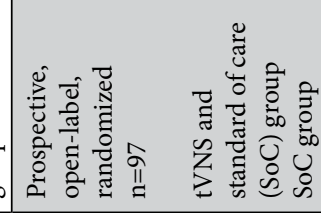 & 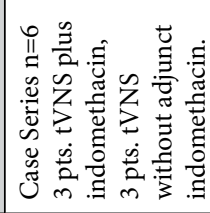 \\
\hline 苞 & 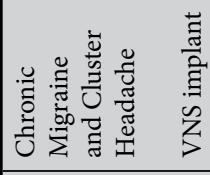 & 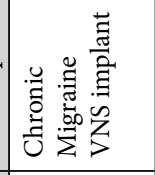 & 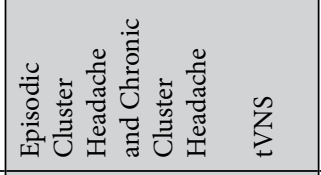 & 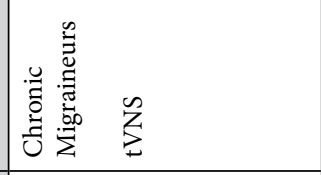 & 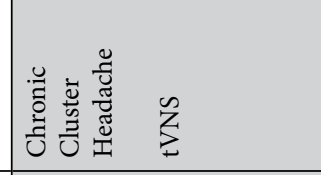 & 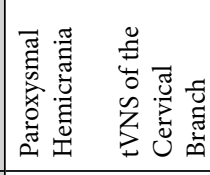 \\
\hline$\frac{2}{\mathscr{D}}$ & 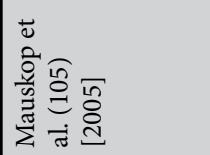 & 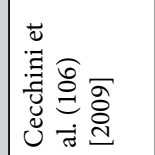 & 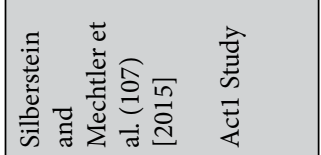 & 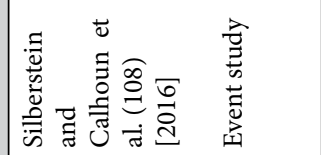 & 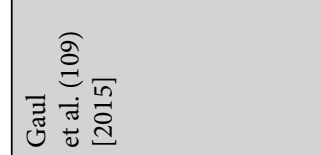 & 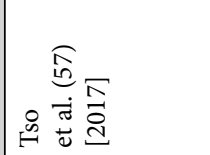 \\
\hline
\end{tabular}


Pain Physician: September/October 2019: 22:447-477

\begin{tabular}{|c|c|c|c|c|c|c|c|}
\hline 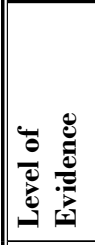 & 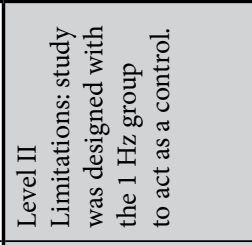 & 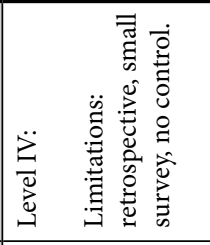 & 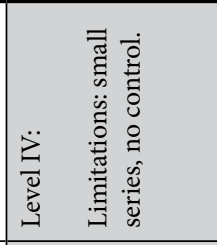 & 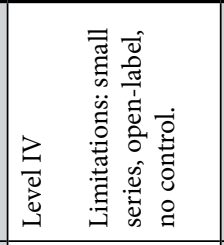 & 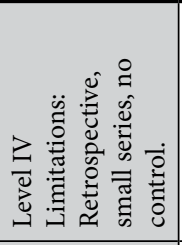 & 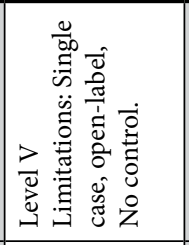 & 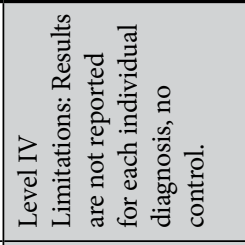 \\
\hline & 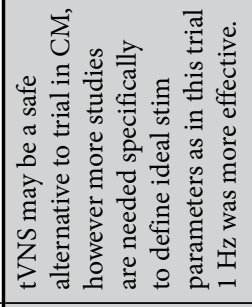 & 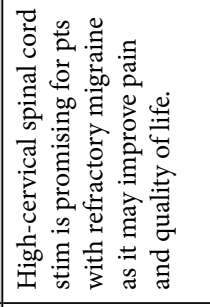 & 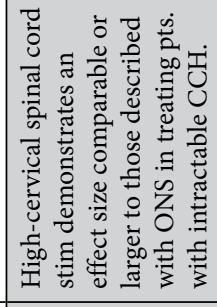 & 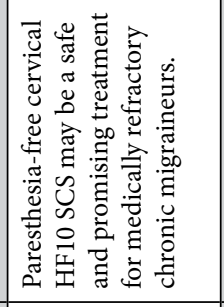 & 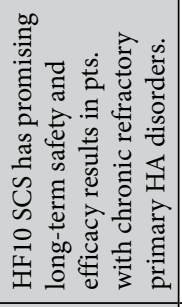 & 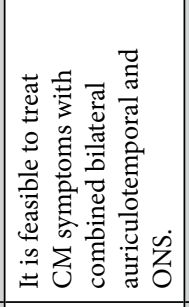 & 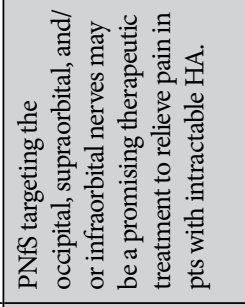 \\
\hline & 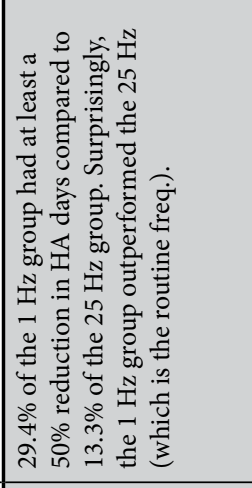 & 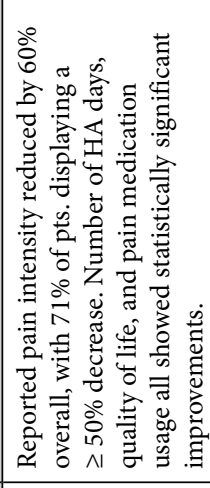 & 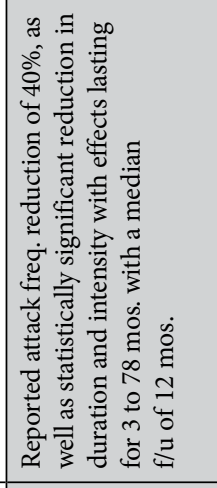 & 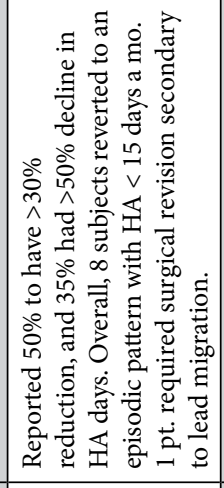 & 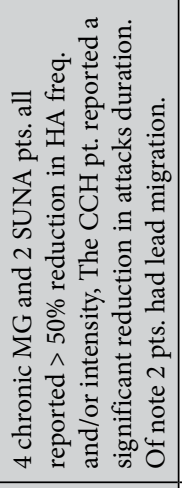 & 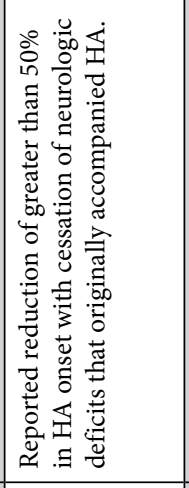 & 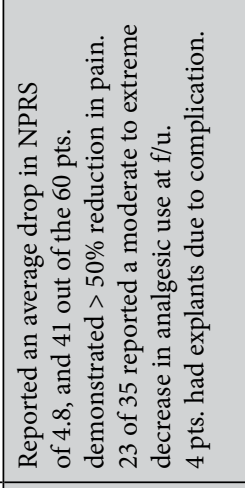 \\
\hline 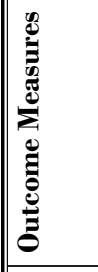 & 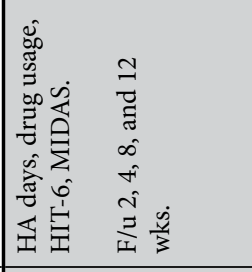 & 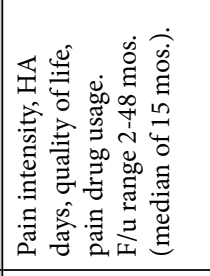 & 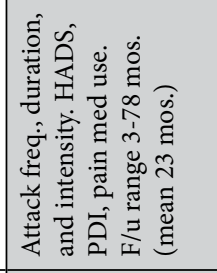 & 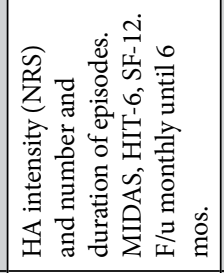 & 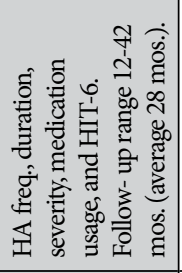 & 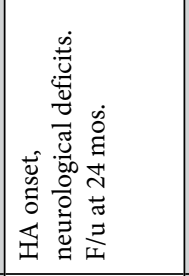 & 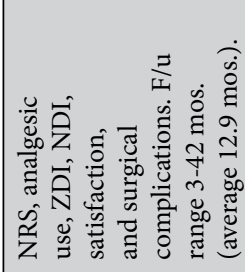 \\
\hline & 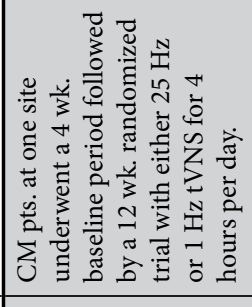 & 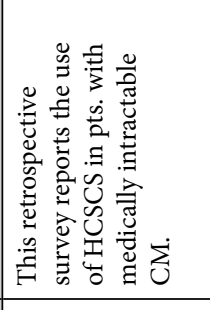 & 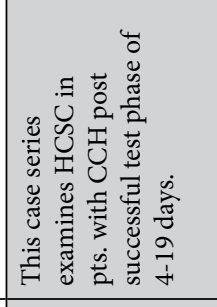 & 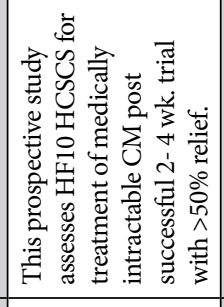 & 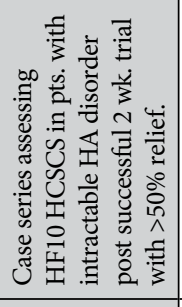 & 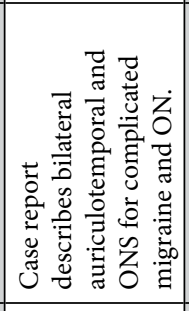 & 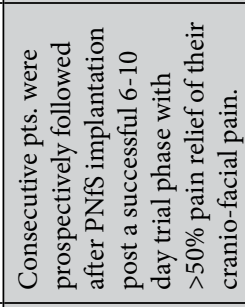 \\
\hline 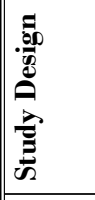 & 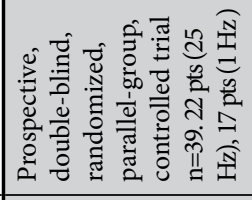 & 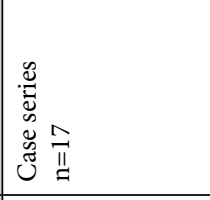 & 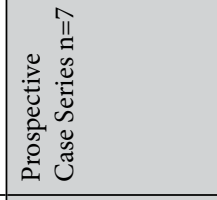 & 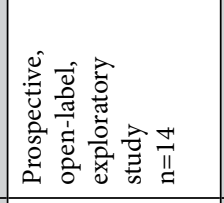 & 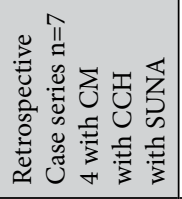 & 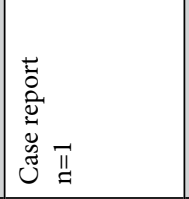 & 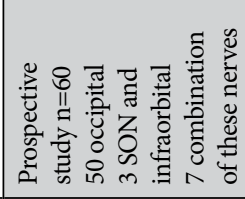 \\
\hline 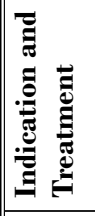 & 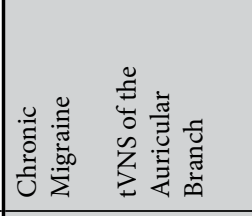 & 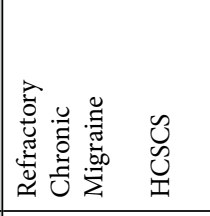 & 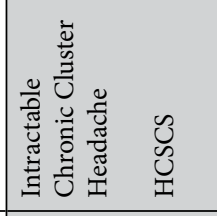 & 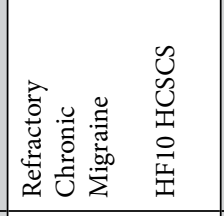 & 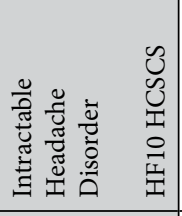 & 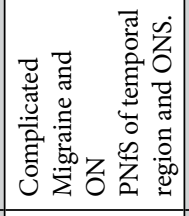 & 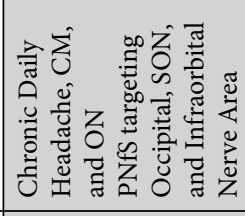 \\
\hline$\frac{2}{D}$ & 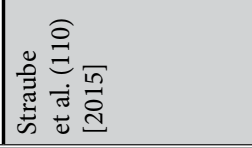 & 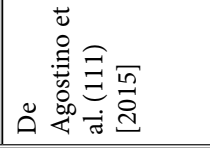 & 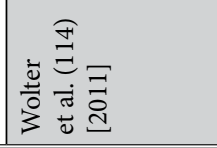 & 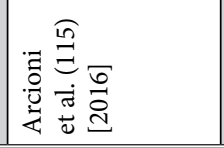 & 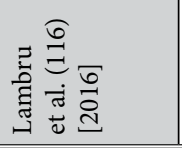 & 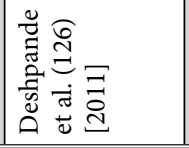 & 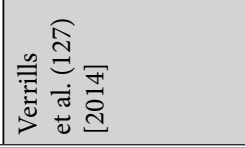 \\
\hline
\end{tabular}




\begin{tabular}{|c|c|c|c|c|c|}
\hline 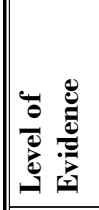 & 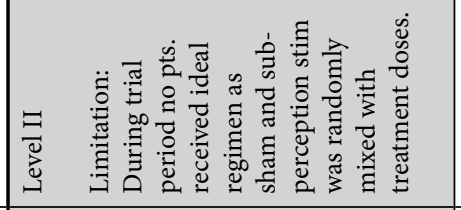 & 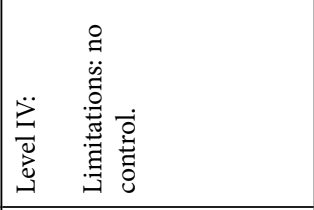 & 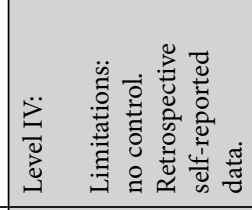 & 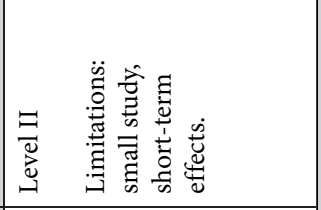 & 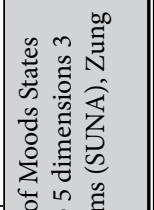 \\
\hline 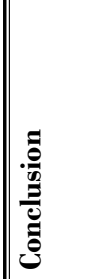 & 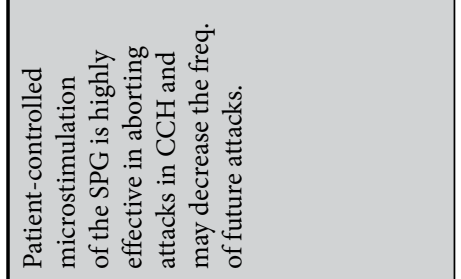 & 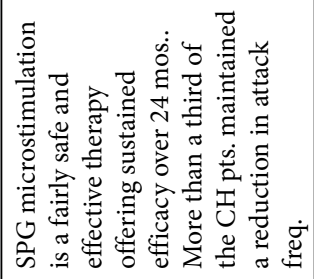 & 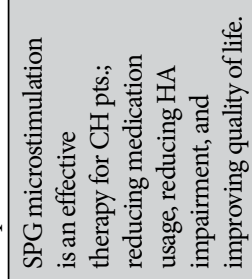 & 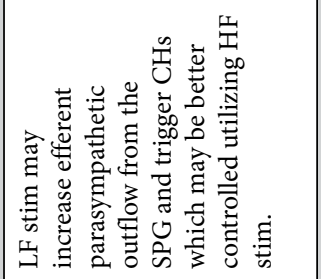 & 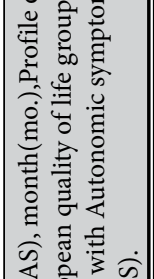 \\
\hline 苞 & 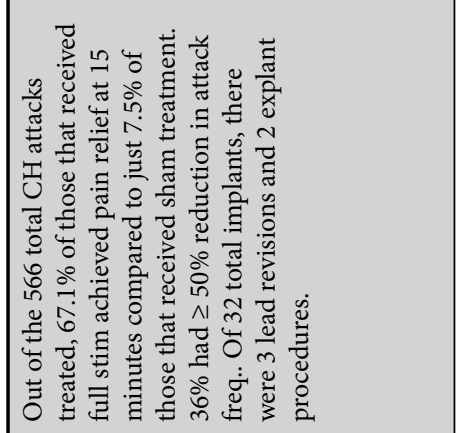 & 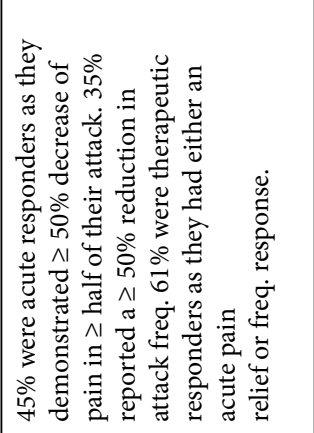 & 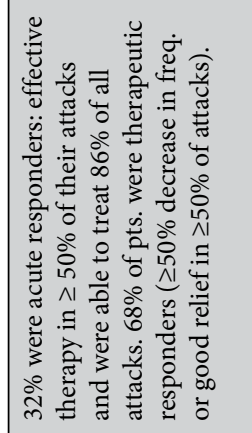 & 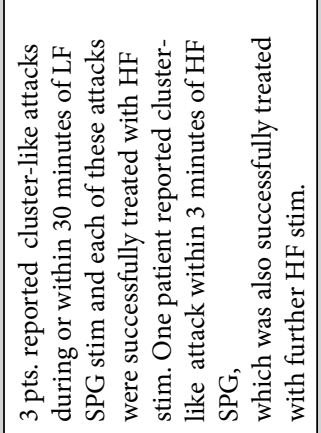 & 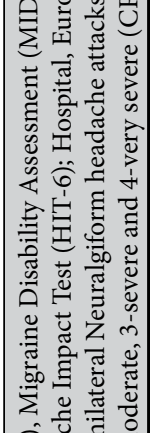 \\
\hline 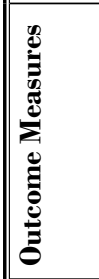 & 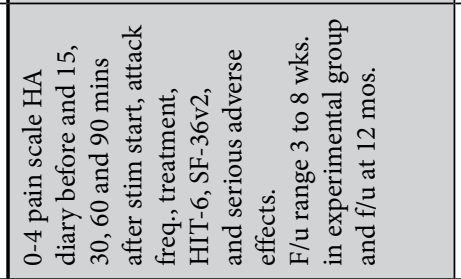 & 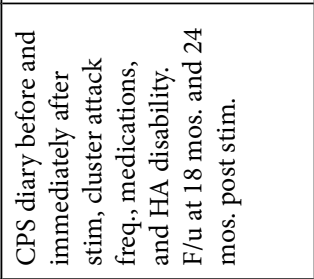 & 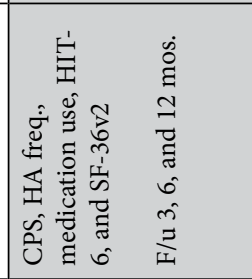 & 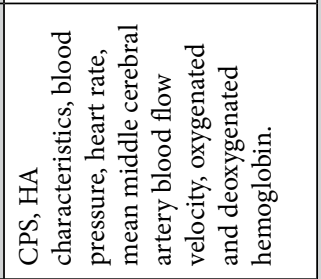 & 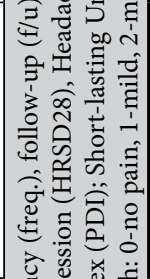 \\
\hline 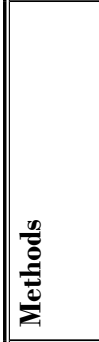 & 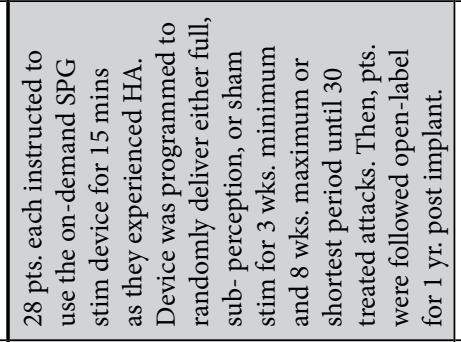 & 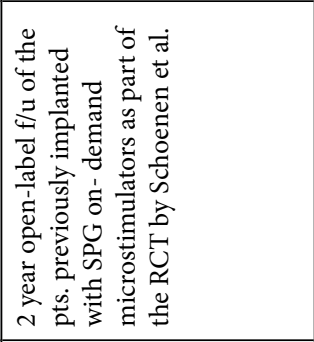 & 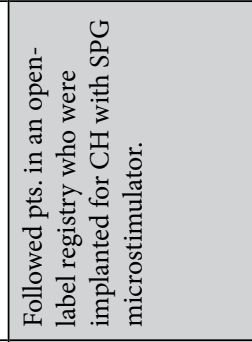 & 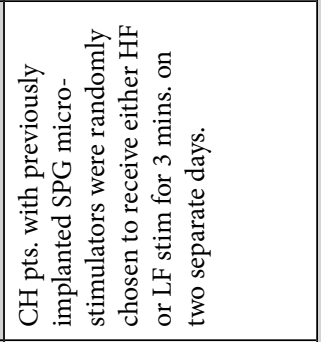 & 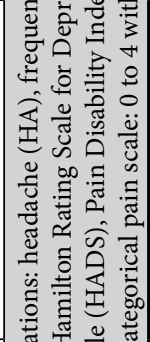 \\
\hline 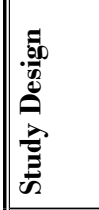 & 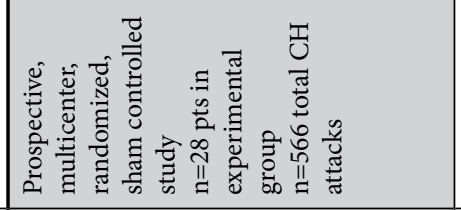 & 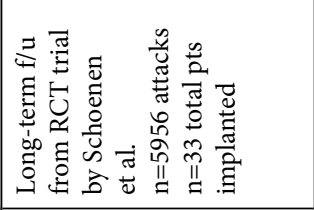 & 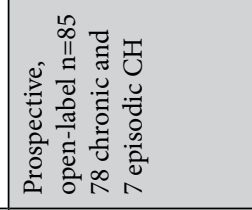 & 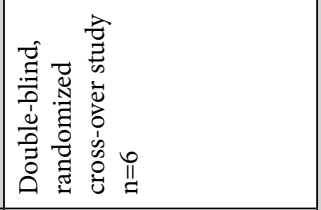 & 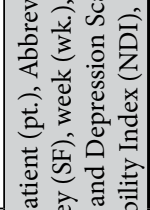 \\
\hline 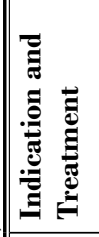 & 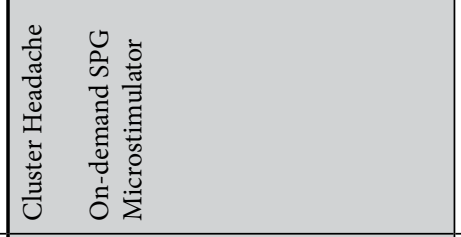 & 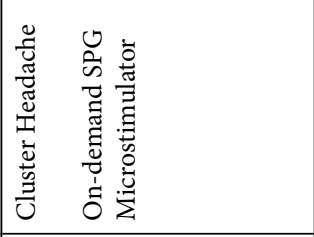 & 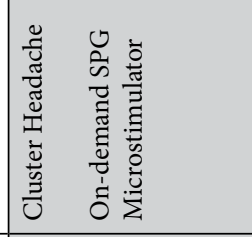 & 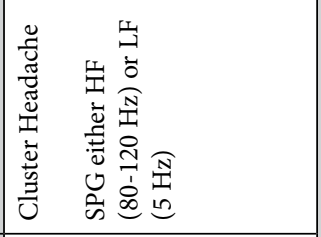 & 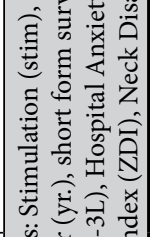 \\
\hline$\frac{2}{E}$ & 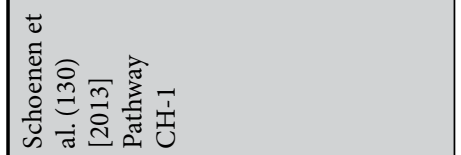 & 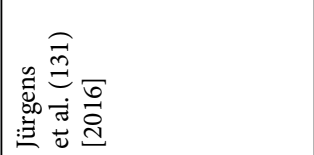 & 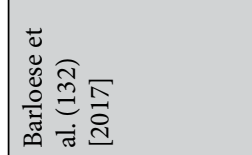 & 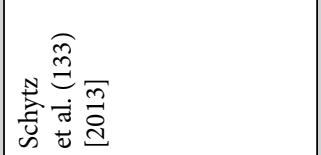 & 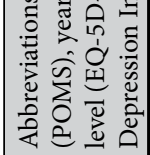 \\
\hline
\end{tabular}




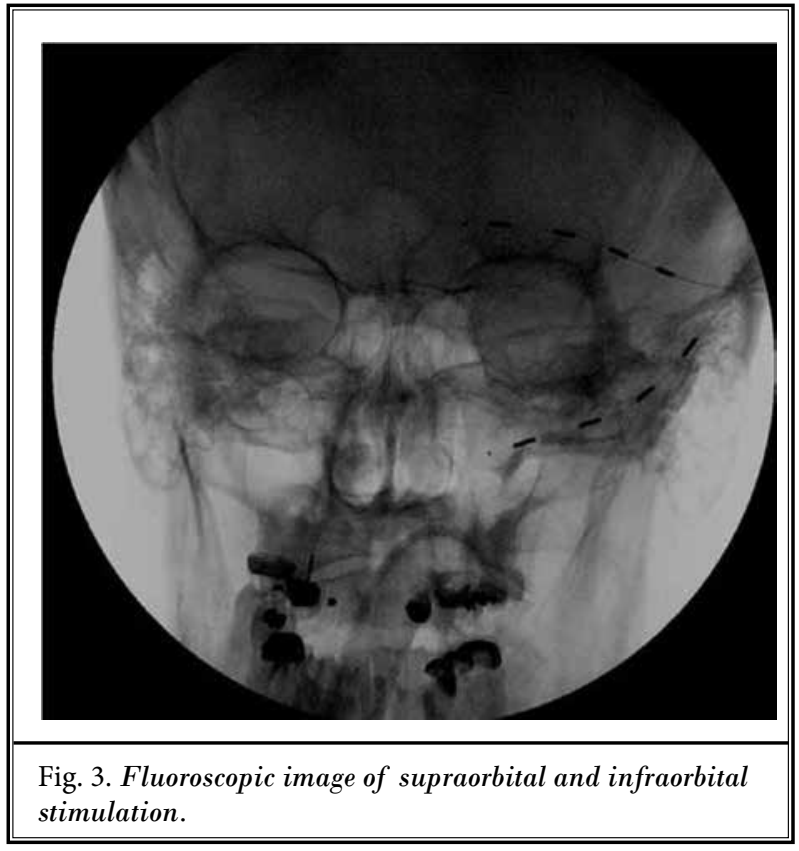

and 3 of these patients had their stimulators removed each secondary to either improvement of pain, loss of efficacy, or generator site infection. Of the remaining patients, 5 out of the $6 \mathrm{had}>50 \%$ pain improvement over a mean 44-month follow-up period. In 2012, Stidd et al (84) presented 3 cases of patients with trigeminal neuropathic pain. The first 2 cases developed chronic facial pain in the ophthalmic and maxillary distribution posttraumatic fractures. After 7- to 10-day successful trials targeting the supraorbital and infraorbital nerves (Fig. 3), both patients underwent implantation with promising results. The third patient suffered from herpes zoster in the ophthalmic distribution. After a successful 7-day trial, the patient was implanted with supraorbital nerve stimulator. Although initial pain relief was substantial, the pain returned secondary to lead migration. After reimplantation, patient continued to report $60 \%$ pain decrease. Interestingly, one case report demonstrates optimal stimulation for facial pain using "cross talk" between one peripherally placed lead at the maxillary nerve and one cervical epidural lead (85). To be further discussed, the branches of the trigeminal nerve remain integral in targeting craniofacial pain. Although evidence for efficacy are limited case series, case reports, and expert consensus guidelines, results have been promising for intractable craniofacial pain.

\section{Supraorbital and Supratrochlear Stimulation}

Similarly, supraorbital nerve stimulation has been shown to be effective for treatment of supraorbital neuralgias, as well as other headache disorders such as $\mathrm{CMs}$ and $\mathrm{CHs}$ (4). Amin et al (86) published a case series of supraorbital PNS in 2008. The study showed marked reduction in pain scores and opioid consumption after 10 of 16 trialed patients were permanently implanted for supraorbital neuralgias. A small case series by Reed et al (87) found that concordant combined occipital and supraorbital neurostimulation may provide effective therapy for both the pain and motor aura in some patients with hemiplegic migraine. Hann et al (88) had similar promising results in a case series involving 14 patients who underwent dual supraorbital and ONS for CMs. A majority of patients reported marked improvement in headache severity and frequency $(71 \%)$, resolution of associated neurologic symptoms $(50 \%)$, and resumption of a normal functional lifestyle (50\%). However, 9 of the 14 experienced a postoperative complication that included lead migration (42.8\%), lead site allodynia (21.4\%), and infection secondary to exposed hardware (14.2\%). Five patients (35.7\%) needed one or more reoperations due to infection, incomplete coverage from stimulation, or near electrode exposure.

In 2013, Schoenen et al (89) reported on a randomized control sham trial on 59 patients with migraine: 30 in treatment group and 29 in sham. They used transcutaneous neurostimulation with self-adhesive electrodes placed over the skin targeting the supraorbital and supratrochlear nerves bilaterally for 20 minutes a day for 90 days (compliance was approximately $60 \%$ for daily stimulation). Interestingly, both groups reported a decrease in migraine days on average by $20 \%$ in the first month. However, at month 3, the decrease in monthly migraine days in the treatment group continued to improve to $29.7 \%$, whereas the initial positive response in the sham group was no longer exhibited. Of note, this trial excluded patients who were using antimigraine treatments in the past 3 months and those who had failed at least 3 preventative drug treatments; these refractory patients are the seemingly helpless patients who surgical implantable stimulation regularly attempts to treat.

In 2012, Vaisman et al (90) reported on a retrospective case series of 5 patients presenting with intractable trigeminal autonomic cephalgia, 4 diagnosed with $\mathrm{CH}$. After implantation of neurostimulation device targeting the supraorbital and supratrochlear nerves, patients on average reduced pain from a mean of 8.9 to 1.6 with an average follow-up period of 25 months. Of note, 2 patients required reimplantations (at 1 and 3 years) 
due to skin erosion with repeat success and 3 patients were completely weaned off of opioids, whereas the other 2 decreased their opioid usage. Supraorbital nerve stimulation, which can cover the supratrochlear region as well with a single lead placement, has positive outcomes in multiple retrospective case series; further research is indicated.

\section{Auriculotemporal Stimulation}

The auriculotemporal nerve is another terminal branch of the trigeminal nerve that has been targeted with PNS. Rodriguez-Lopez et al (91) conducted a small prospective case series in 2015 for 6 patients with TMJ syndrome that did not respond to intraarticular local anesthetic or corticoid steroid injections. With PNS of the auriculotemporal nerve (Fig. 4), the group reported an average of $72 \%$ pain relief with the majority of patients discontinuing analgesic medications. One case report followed a patient treated with bilateral auriculotemporal nerve stimulators for $\mathrm{CM}$. Pain intensity decreased from 8-9 to 5 at the 16-month follow-up. In addition, migraine disability assessment went from total disability to mild disability as photophobia and pain were better controlled (92). The auriculotemporal nerve has been used for targeted PNS to treat migraine headache and jaw pain with promising efficacy.

\section{Halo $360^{\circ}$ Cranial Stimulation}

The halo $360^{\circ}$ cranial stimulation with the unique placement of a novel device aims to provide a wide array of coverage across the bilateral head to treat headaches, primarily migraines. This technique used 4 leads each with 8 electrode contacts and all powered by one single implantable pulse generator, thus allowing for a greater number of contacts over previous devices. Bilateral leads are placed superior to the ear and anteriorly to stimulate the supraorbital, supratrochlear, zygomaticotemporal, and auriculotemporal nerves. In addition, bilateral leads are placed posteriorly to stimulate the greater and lesser occipital, greater auricular, and branches of the third occipital nerve, and the posterior rami of C2 and C3 nerve roots (93). This comprehensive method requires further investigation for efficacy.

\section{Occipital Nerve Stimulation}

ONS has been used to treat occipital neuralgia refractory to conventional medical management. Because of its mechanism and efficacy, the occipital nerve is one of the most studied targets for head and neck pain. With the greater and LONs being distal branches of $\mathrm{C2}$

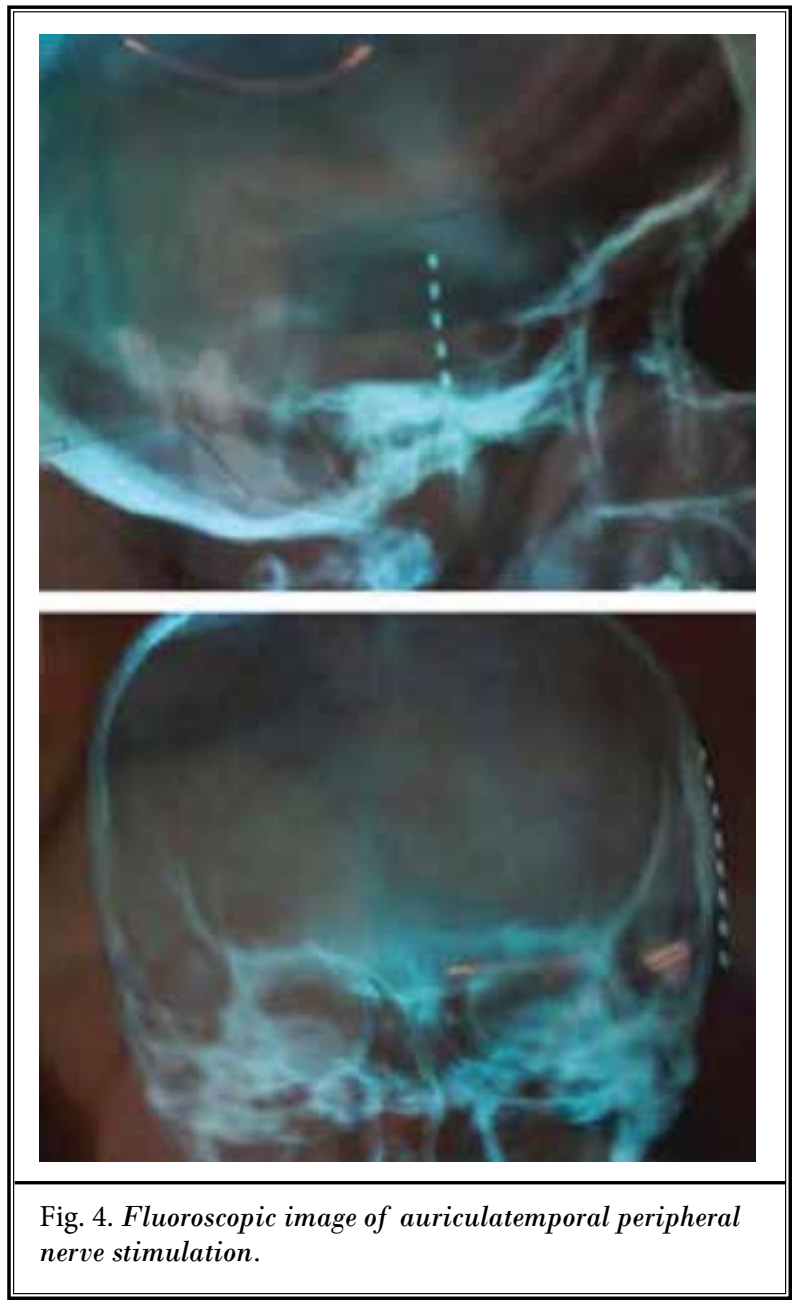

and C3, the mechanism of action is thought to involve modulation of peripheral and central nociceptive inputs (94) (Fig. 5). Regional cerebral blood flow has also been shown to increase after ONS in migraineurs, an encouraging finding in the treatment of neurovascular headache (95).

A study looked at 10 patients being treated for drug refractory chronic $\mathrm{CH}$ with ONS. Cranial positron emission tomography scans of 4 chronic stimulator patients and 6 patients scanned prestimulator implantation and postimplantation demonstrated that ONS has a neuromodulator effect in the central pain matrix, suggesting that the ONS works to reduce the ipsilateral hypothalamic hyperactivity that can be found in acute episodic $\mathrm{CH}$ attacks (96).

One case series focusing on occipital neuralgia followed 13 patients who underwent a total of 17 peripheral suboccipital stimulation implants (Fig. 6) for 


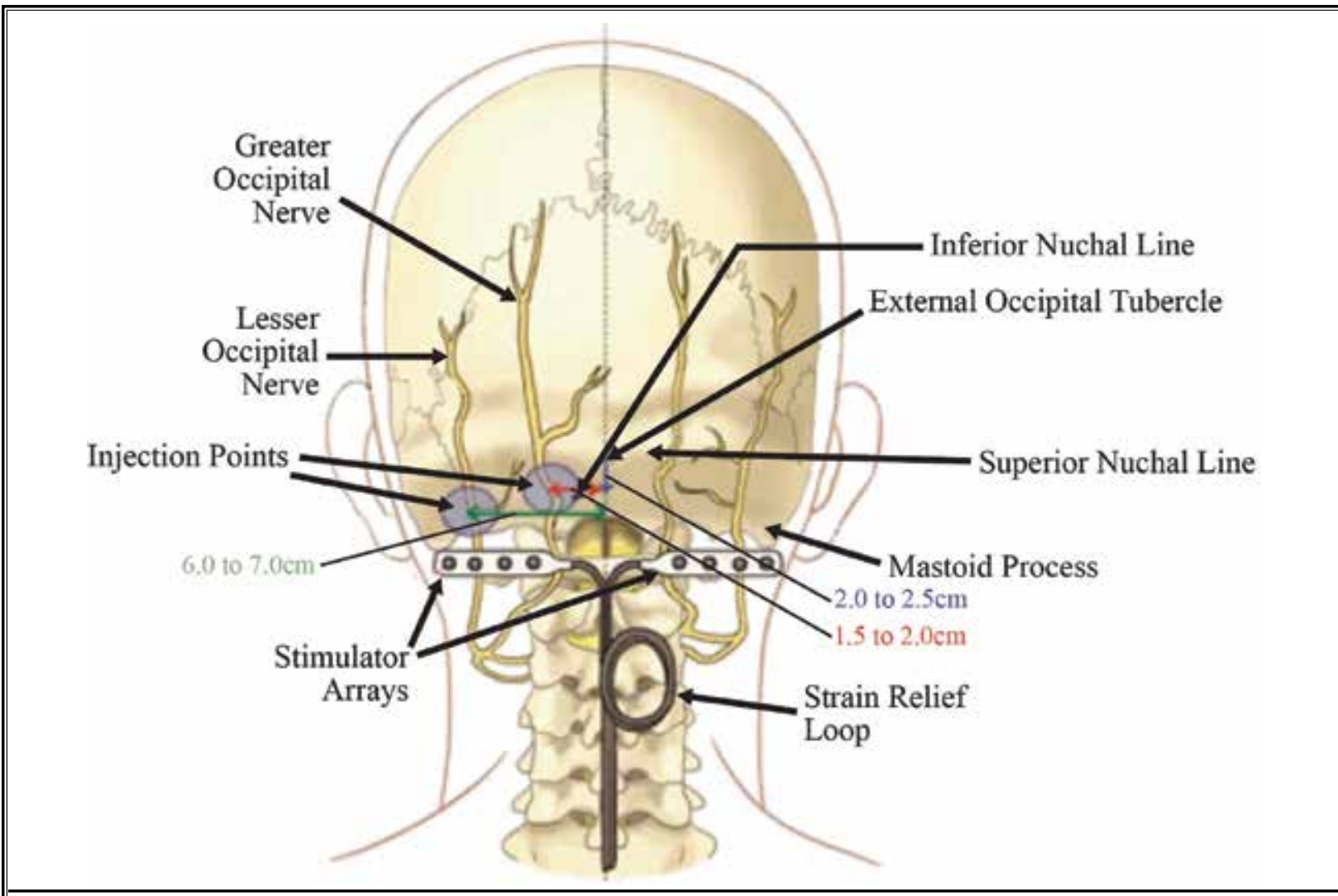

Fig. 5. Diagram of occipital nerve stimulation placement.

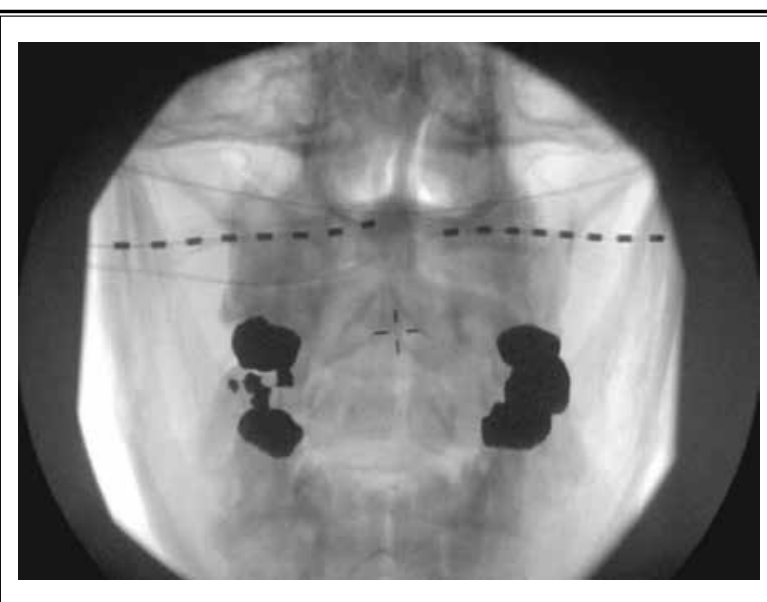

Fig. 6. Fluoroscopic image of occipital nerve stimulator.

intractable occipital neuralgia. To differentiate from migraines, each patient was required to demonstrate some response to local occipital nerve or selective C2 root block. The target for stimulation was the occipital nerve trunk at the level of $\mathrm{C} 1$. In this series of cases, over an average of 2-year follow-up, $66 \%$ of patients had excellent responses reported at $>75 \%$ pain relief. The remaining 33\% demonstrated good responses with at least 50\% pain relief(97). Similarly, Kapural et al (98) described 6 patients with severe refractory occipital neuralgia who were treated with ONS at C1 through a midline approach. At 3-month follow-up, there was a significant change in pain and disability.

The GON has been a promising target for PNS for not only occipital neuralgia, but a variety of other painful conditions of the head and neck, including both primary and secondary headache disorders (4). Contrary to other PNS targets for head and facial pain, there have been prospective, RCTs reported on the use of ONS. The ONSTIM trial was a prospective, multicenter, singleblinded, feasibility RCT sponsored by Medtronic Inc. using ONS for chronic intractable migraine (99). Patients were randomized into adjustable stimulation $(n=28)$, preset stimulation ( $n=16)$, and medical management $(n=17)$ groups. At 3 months after implantation, $39 \%$ of patients in the adjustable stimulation group showed 
a reduction in headache days per month or a $>3$ point reduction in pain scores. Of note, $24 \%$ of implanted patients were noted to have lead migration in the study. This led the authors to conclude that although the data collected were promising for the treatment of migraines using ONS, more studies are needed in this area (100).

Another prospective RCT using ONS was sponsored by St. Jude Medical (101). This multicenter, doubleblinded, controlled study used ONS trials followed by both active stimulation implants and sham implants in 157 patients with 125 meeting the criteria for intractable CM. Approximately two-thirds of the patients were randomized into the active stimulation implanted group by design. The study failed to show a significant difference in the sham versus active stimulation group in the primary endpoint, a reduction in daily mean Visual Analog Scale (VAS) pain scores by $50 \%$ at 3 months. However, there was a significant difference shown between the 2 groups in patients reporting a 30\% reduction of daily VAS scores. Dodick et al (102) followed this by reporting one-year data in the study. A significant reduction in number of headache days and headache disability indices were reported along with encouraging reductions in headache intensity. Unfortunately, a high number of patients $(70 \%)$ suffered a postoperative adverse event, nearly half ( $40 \%)$ of which required surgical intervention. The authors concluded that although results support the 12-month efficacy of PNS of the occipital nerves for headache pain and disability, more emphasis on adverse event mitigation is needed in future research. A recent review and meta-analysis of ONS for CM included several additional older RCTs and 7 case series (22). It concluded that although efficacy for ONS in migraine over sham has been established, "the average effect size is modest" and "further measures to reduce the risk of adverse events and revision surgery are needed (22)."

Focusing on CHs, Burns et al (103) analyzed 8 patients who had been implanted bilaterally with ONS for control of medically intractable chronic $\mathrm{CH}$. The results of this open-label, case series were promising at a median follow-up period of 20 months: 2 patients noted a substantial improvement, 3 patients showed moderate improvement, and 1 reported mild improvement. Of note the first patient was implanted on ipsilateral side to where $95 \%$ of the attacks were located, after stimulation the geographic nature of the attacks changed, and thus bilateral stimulators was placed. From then on, each patient was implanted bilaterally. During device malfunctions, including battery depletion, the patients reported a return of symptoms. A total of 6 out of the 8 patients would recommend the procedure. Overall, these cases suggest ONS for $\mathrm{CH}$ is promising. Of all the neuromodulation studies involving PNS for face or head pain, the ONS currently has the greatest level of supporting evidence for treatments including migraine, $\mathrm{CH}$, and occipital neuralgia.

\section{Vagal Nerve Stimulation}

Vagal nerve stimulation (VNS) has shown efficacy in various conditions with success first illustrated in epilepsy and depression. VNS affects the parasympathetic nervous system and can result in changes in blood brain flow. Although the exact mechanism is not defined, patients with epilepsy treated with VNS were noted to simultaneously have improvements in their headaches. A retrospective case series looked at 34 patients who had been treated with prior VNS, and 10 patients were identified with a prior history of migraines. A total of 8 out of 10 of these patients with migraine reported a reduction of monthly frequency by at least $50 \%$ in the first 3 months poststimulator surgical implantation. Although the frequencies of reported migraines were small leading to large percent changes and there is potential for retrospective recall bias, this study highlighted the need for further investigation (104). A series of 6 cases concluded that 2 out of 2 chronic $\mathrm{CH}$ patients had good results with VNS, and 2 out of 4 patients with CM reported excellent relief, whereas the other 2 had poor efficacy (105). Another case series selected 4 patients suffering from drug-refractory CM with depression for trial with implanted VNS set to $30 \mathrm{~Hz}$. The authors concluded that 2 of the 4 patients improved for both headache and depression at 1 to 3 months postimplant. Clinical trials are recommended to better determine efficacy (106).

Several studies have focused on noninvasive or transcutaneous vagal nerve stimulation (tVNS). In 2016, Silberstein et al (107) reported on their use of tVNS to treat patients with either episodic $(67 \%)$ or chronic $(33 \%) \mathrm{CH}$. On initial feelings of attack, patients were instructed to manually deliver 3 consecutive 2-minute stimulations to the right side of the neck. Response was then assessed at 15 minutes. This randomized, double-blind, sham-controlled study with 60 patients in treatment group and 73 in sham group displayed in the cohort previously diagnosed with episodic $\mathrm{CH}$ there was a positive response rate, defined as the percent of patients with a pain score of 0 or 1 on a 5-point scale. 
However, in the total population no significant difference between sham and treatment groups was established. This suggests that tVNS may best treat those with episodic CH. Similarly, in 2016 Silberstein et al (108) studied noninvasive tVNS and this time in chronic migraineurs. In this randomized, sham-controlled trial, the treatment group $(n=30)$ and sham group $(n=29)$ did not statistically differ after 2 months. Following this, 27 patients were followed through to 6 months with open-label treatment. At month 8 , for the 15 patients who completed treatment the decrease from baseline in headache days was 7.9 and reached statistical significance. At 6 months $38.5 \%$ and at 8 months $46.7 \%$ of patients achieved $>50 \%$ response. Although there was a high loss to follow-up with increasing time that may lead to overrepresentation among responders or regression to the mean, this study suggests that longterm use may be necessary before migraine prophylaxis response is achieved. Gaul et al (109) analyzed 48 patients with chronic $\mathrm{CH}$ treated with tVNS with a control of 49 treated with standard of care. Those treated with tVNS had a statistically significant reduction in number of attacks per week with a mean of 3.9 fewer attacks than the control group. This study further suggests the efficacy of tVNS for $\mathrm{CH}$. A case series examined 6 patients with $\mathrm{PH}$ that were treated with tVNS with regimens ranging from 2 to 4 doses given either 2 times a day or 3 times a day. A total of 4 of the 6 reported benefits in either frequency or severity from this treatment ranging from 3 months to 5 years (57).

Another study examined tVNS in patients with migraines to target the auricular nerve (a branch of the vagus) at the concha of the outer ear. This parallelgroup randomized trial analyzed 22 patients who received $25 \mathrm{~Hz}$ stimulation and 17 patients who received $1 \mathrm{~Hz}$ stimulation for a total of 12 weeks. A total of $29.4 \%$ of the $1 \mathrm{~Hz}$ group had at least a $50 \%$ reduction in headache days. Contrary to the authors' hypothesis, the $1 \mathrm{~Hz}$ group outperformed the $25 \mathrm{~Hz}$ (which is the routine frequency commonly used in VNS implants for other conditions) (110). Overall these studies suggest that both VNS and tVNS may be safe alternatives to trial, however, more studies are needed specifically to define ideal stimulation parameters.

\section{Spinal Cord Stimulation}

\section{High Cervical Spinal Cord Stimulation}

The use of dorsal column stimulation in the high cervical region has been used to treat headache and facial pain. Neurons projecting from the trigeminocervical complex to the trigeminal nucleus caudalis can be stimulated at C2-C3 (Fig. 7), potentially covering both facial and occipital pain (94). For refractory migraine headaches, one retrospective survey showed high cervical lead placement led to a decrease in pain intensity (with $71 \%$ of patients reporting a decrease of $50 \%$ or more), headache days, and medication usage at a follow-up period with a median of 15 months. However, the study size was small $(n=17)$, and further evidence is needed in this area (111). Cases have been reported of successful use of high cervical spinal cord stimulation (HCSCS) to treat CHs (112) and posttraumatic headaches as well (113).

After success with one patient with medically intractable chronic $\mathrm{CH}$, Wolter et al (114) reported on a case series of 7 patients. In all patients, an initial lead was placed slightly paramedian ipsilateral to the pain location. The electrode was directed cranially until movement was halted by the occipital bone or the posterior arch of the atlas. Paresthesias covered root C2 and ophthalmic nerve with some maxillary branches. In 2 patients, contralateral leads were placed one at 6 months and one at 7 years both secondary to shift of $\mathrm{CH}$ pain location. This study concluded that all patients had statistical differences in attack frequency, duration, and intensity, and half of the patients stopped all medication postimplantation. These results are promising with an attack frequency reduction of $40 \%$, and effects lasting for 3 to 78 months with a median follow-up of 12 months. In 2016, Arcioni et al (115) reported on a prospective, open-label, exploratory study in which 17 patients diagnosed with refractory $\mathrm{CM}$ underwent a trial of paresthesia-free cervical high frequency $10 \mathrm{kHz}$ (HF10) SCS. The target for stimulation was the dorsal columns in the area corresponding to $\mathrm{C} 2-\mathrm{C} 3$ vertebral level. There was one trial failure, one trial infection, and one implant infection. The other 14 patients had successful implants that remained at the 6-month follow-up. A total of 7 out of the 14 were reported to have $>30 \%$ reduction in headache days, and 5 out of 14 had $>50 \%$ reduction in headache days. Overall, 8 subjects reverted to an episodic pattern experiencing headaches < 15 days a month. One patient required surgical revision secondary to lead migration.

Similarly, in 2016, Lambru et al (116) reported on the use of paresthesia-free HF10 SCS for intractable headache disorder. The target for continuous stimulation was also the dorsal columns at $\mathrm{C} 2-\mathrm{C} 3$. This population of 7 patients included 4 with CM, 1 with chronic 


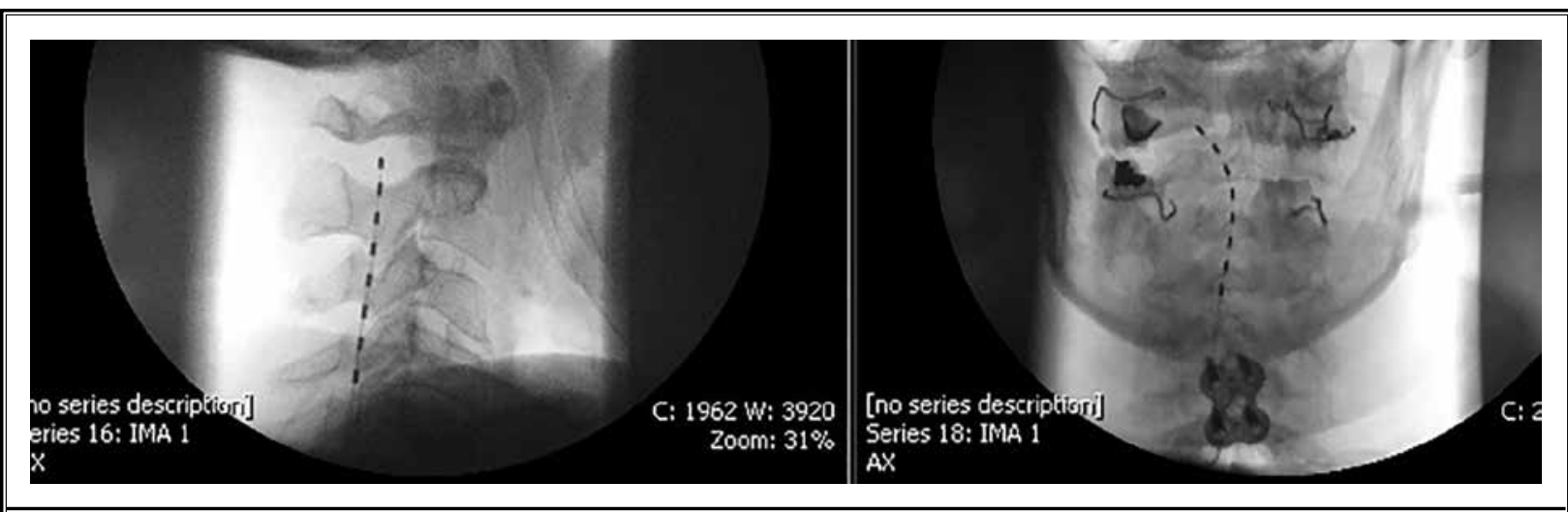

Fig. 7. Fluoroscopic image of high cervical spinal cord stimulator.

$\mathrm{CH}$, and 2 with chronic short-lasting unilateral neuralgiform headache attacks with autonomic symptoms. The $4 \mathrm{CM}$ patients all exhibited at least $50 \%$ reduction in headache frequency and/or intensity; the chronic $\mathrm{CH}$ patient reported a significant reduction in attack duration. Overall range of follow-up was from 12 to 42 months. Two patients underwent revisions secondary to lead migration. Secondary to this promising data, we are hopeful that HF10 SCS will continue to prove to be an effective headache treatment.

Reported in 2011, Tomycz et al (117) reviewed the literature for cervicomedullary junction SCS to alleviate head and facial pain. They conclude that patients with trigeminal deafferentation pain, trigeminal neuropathic pain, and PHN may respond favorably, and patients with occipital neuralgia are likely not to benefit. A single-center retrospective case series analyzed 12 patients who underwent HCSCS for facial pain syndrome (the vast majority with trigeminal neuropathy, one with TN, and 2 with neuropathic facial pain). The authors conclude that $>60 \%$ of patients had effective pain relief (118). Similarly, in 2018, Velásquez et al (119) retrospectively reported on 12 patients diagnosed with trigeminal neuropathic pain at varying and sometimes multiple nerve divisions (42\% with ophthalmic, $75 \%$ with maxillary, and 33\% with mandibular). Mean follow-up period was 4.4 years. The average change in Numeric Rating Scale was from a baseline of 7 to postimplantation of 3 . There was a $57.1 \%$ overall pain reduction, however long-term failure rate was $25 \%$ with 2 patients not having relief and 1 patient having a late biological failure at one year. Access for implantation was performed by a midline partial C1 laminectomy to place the epidural paddle slightly lateralized to the affected side. In $75 \%$ of patients, leads were placed at $\mathrm{CO}-\mathrm{C} 1$ and in $25 \%$ the upper contact was below $\mathrm{C} 1$. Tonic stimulation was used in all patients. Mean follow-up period was from 0.3 to 21.1 years, with an average of 4.4 years. During this period there were a total of 19 system revisions mostly related to not ideal positioning, malfunction, or disconnection.

Furthermore, Papa et al (120) reported a case report on successfully using SCS to treat a case of refractory Eagle's syndrome to both conservative treatments and surgery. $10 \mathrm{KHz}$ SCS was placed between C2 and C7. Patient's pain relief went from 10 to 4 , and there was complete relief from a prior persistent foreign body sensation in the throat. Because of the patient's delayed diagnosis of over 20 years, the authors suggest the pain had become centralized. Although clearly it has been demonstrated effective in small studies and case reports, larger studies showing long-term efficacy for high cervical leads to treat headache and facial pain are lacking.

\section{Peripheral Nerve Field Stimulation}

Peripheral nerve field stimulation (PNfS) targets the subcutaneous small fiber nerve endings of peripheral nerves, not necessarily correlating with the distribution of a single "named" nerve (2). A recent cohort in 2016 of 10 patients with intractable facial pain in the trigeminal distribution who were trialed with PNfS: 8 of the 10 proceeded to implant and reported significant pain relief, and 2 of these patients reported an absence of pain after implant (121). Similar results were seen in another case series of 6 total drug-resistant patients: 2 with classical TN, 2 with concomitant persistent facial pain, and 2 with postherpetic trigeminal neuropathy. Average pain intensity decreased by 


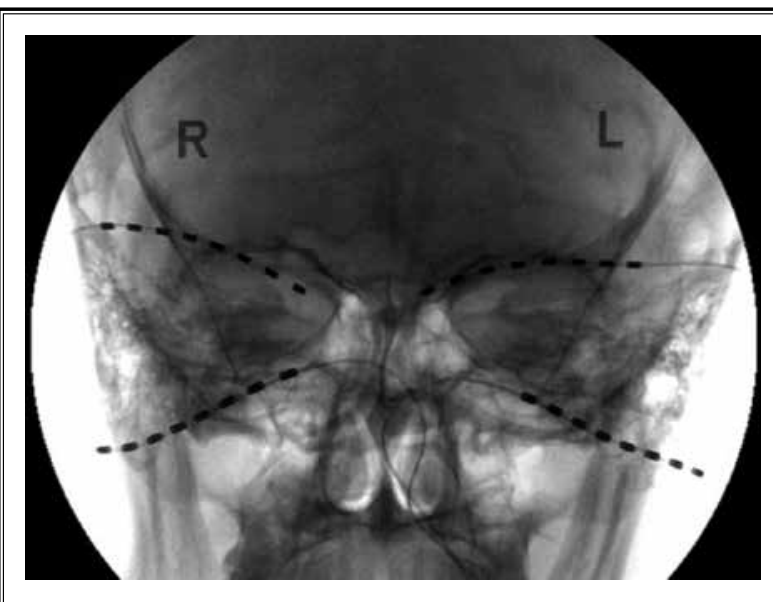

Fig. 8. Fluoroscopic image of bilateral supraorbital and occipital nerve PNfS.

$83 \%$ and number of attacks decreased by $73 \%$ with a mean follow-up of 15.2 months. A total of 5 out of the 6 patients reduced their pain medication intake. One patient developed a device infection at 4 months, and after a relapse of pain underwent a second implantation that was successful. Overall, this case series shows effective treatment with PNfS for classic TN and facial pain (122).

Additional case reports have demonstrated effectiveness using PNfS for atypical facial pain (123). One patient with axial neck pain had $100 \%$ relief and reduction in opioids postplacement of PNfS to the paraspinal and trapezius muscles (124). Two PHN patients displayed successful pain relief postimplantation in the lateral thoracic region with PNfS (125). A second case report looked at combining ONS with bilateral subcutaneous electrical stimulation over the temporal region to treat a patient diagnosed with complicated migraine and occipital neuralgia. At 2-year follow-up, the headache onset was reduced by $>50 \%$, and there was a cessation of neurologic deficits that had been seen with previous attacks (126). In 2014, Verrills et al (127) reported on 60 patients with either chronic daily headache, occipital neuralgia, or CM who underwent successful trial and later PNfS implantation with 50 targeting the occipital, 3 the supraorbital and infraorbital, and the remaining 7 were a combination of these 3 nerves (Fig. 8). Outcomes were successful with average reduction in pain scores of 4.8 , and overall 41 out of the 60 patients demonstrated at least $50 \%$ reduction in pain. Although prospective trials are lacking, PNfS has shown promise as a treatment for debilitating refractory facial pain.

\section{SPG Stimulation}

Neurostimulation of the SPG is a relatively novel and promising treatment modality for refractory craniofacial pain. A 7-patient monocentric case series examined SPG and Gasserian ganglion stimulation for facial pain with most patients diagnosed with persistent idiopathic facial pain. A total of 5 of the 7 patients proceeded to permanent implantation: one patient had stimulation of the SPG; 3 patients had stimulation of SPG combined with peripheral nerve branches either the supraorbital, auriculotemporal, and occipital; and one patient had a Gasserian ganglion only implant for trigeminal neuropathic pain. A total of 4 out of 5 , including several of the SPG implanted patients and the one Gasserian ganglion only implant, experienced sustained pain relief, which was reported out to 24 months, with a mean of 9.6 months (128). Of note, paresthesia-free stimulation was reported in several of the SPG stimulation cases. Due to multiple implant targets in most patients, the efficacy obtained from the SPG alone is difficult to deduce. Another case report describes successful SPG stimulation for intractable facial pain, after failure of SPG block with local anesthetic, which resulted in cessation of opioids and significant pain relief (129).

In addition to craniofacial pain, stimulation of the SPG has been well described for $\mathrm{CH}$. In 2013, Schoenen et al (130) conducted a multicenter trial (Pathway $\mathrm{CH}-1$ ) comparing on-demand ipsilateral Autonomic Technologies Inc. SPG microstimulation at HF (average $120 \mathrm{~Hz}$ ) and subthreshold amplitudes versus sham stimulation for $\mathrm{CH}$ attacks. The 28 patients were implanted targeting the SPG (Fig. 9) and were instructed to use the handheld remote controller to activate stimulation for 15 minutes as needed when they experienced a moderate pain intensity headache. The devices were programmed to at different times randomly deliver each of 3 types of stimulation: full stimulation, subperception stimulation, or sham stimulation. Out of the 566 total $\mathrm{CH}$ attacks treated, $67.1 \%$ of those that received full stimulation achieved pain relief at 15 minutes compared to just $7.5 \%$ of those that received sham treatment. This study demonstrated statistically significant results in favor of SPG stimulation. In 2016, an open label follow-up study of the original Pathway $\mathrm{CH}-1$ results showed $45 \%$ of 33 patients were acute responders as they demonstrated at least a $50 \%$ decrease of pain in at least half of their attacks through the 24-month review period. Some $35 \%$ of the 33 patients reported a $50 \%$ reduction in attack frequency, $61 \%$ were therapeutic responders as 
they had either an acute pain relief or frequency response, and $30 \%$ of the patients were found to have a remission period lasting at least one month. The authors conclude that self-administered SPG stimulation is effective in the acute period, reduces attack frequency, and may induce a state of remission thereafter (131). Similarly in 2018, Barloese et al (132) reported on another open-label prospective study for 12 months in which 85 patients (78 with chronic $\mathrm{CH}$ and 7 with episodic $\mathrm{CH}$ ) were implanted with a SPG microstimulator. A total of $32 \%$ of patients were acute responders meaning they had effective therapy in at least half of their attacks. These active responders were able to treat $86 \%$ of their attacks. Some $65 \%$ of all subjects were therapeutic responders in that they had $50 \%$ reduction in attack frequency or achieved effective therapy in at least half of all attacks. Quality of life scores were significantly improved at 12 months compared to baseline.

In 2013, Schytz et al (133) reported on a double-blind cross-over study in which 6 patients with $\mathrm{CH}$ who were previously implanted with a SPG neurotransmitter were randomly allocated to receive $\mathrm{HF}$ (80-120 Hz) or low frequency (LF, 5 $\mathrm{Hz}$ ) stimulation for 3 minutes on 2 separate days. Three patients reported cluster-like attacks during or within 30 minutes of LF SPG stimulation, and each of these attacks were successfully treated with HF stimulation. One patient reported a clusterlike attack within 3 minutes of HF SPG stimulation, which was also successfully treated with further HF stimulation. This suggests that efferent parasympathetic outflow from the SPG can trigger $\mathrm{CHs}$ that may be better controlled using HF stimulation. HF stimulation of the SPG for

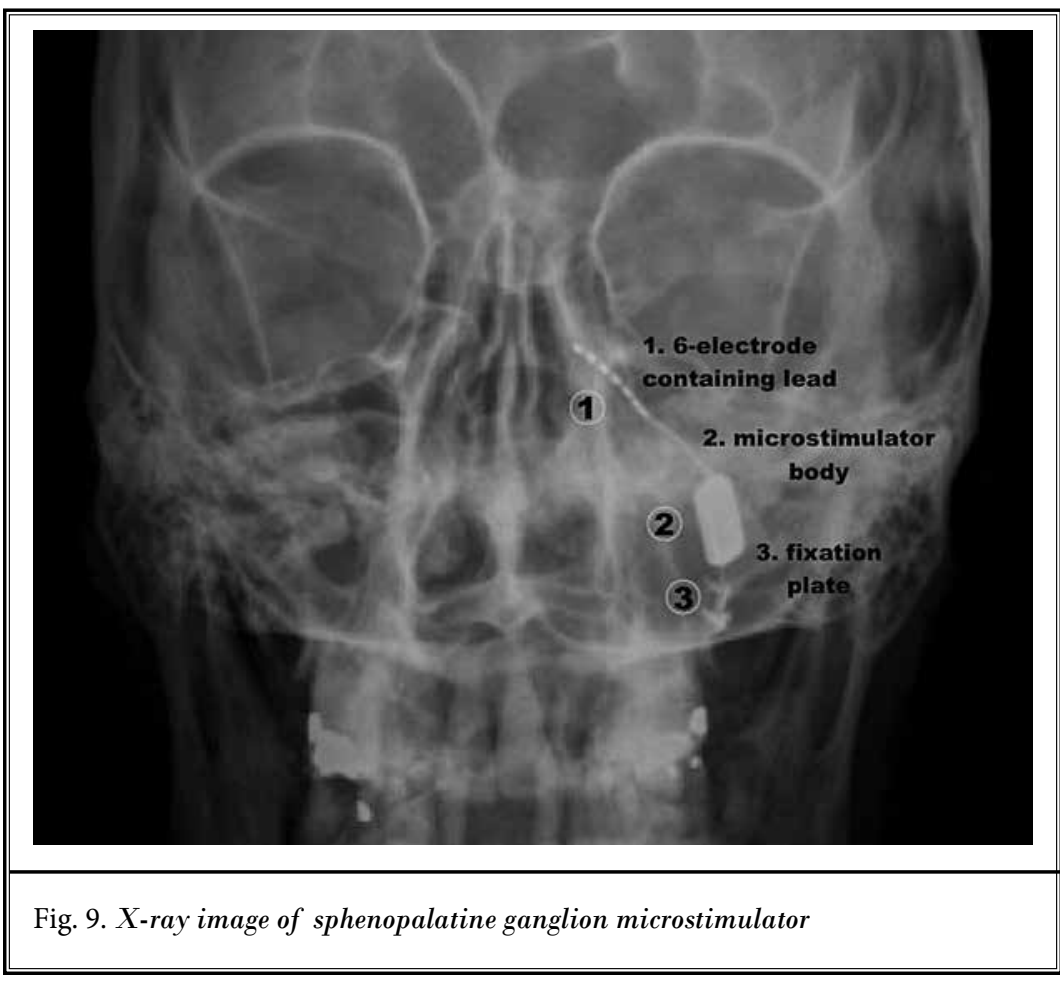

refractory $\mathrm{CH}$ is now recognized by expert consensus groups and guidelines have been published, becoming commercially available and approved in Europe (134). It appears that long-term powered prospective studies may be feasible considering that efficacy has been shown with this therapy. Studies are ongoing to evaluate the role in acute and preventive treatment of migraine headaches with SPG stimulation (135).

\section{Gasserian Ganglion Stimulation}

The Gasserian ganglion of the trigeminal nerve, as discussed, has been a target of stimulation. Reported in 1997, Taub et al (80) described a series of 34 total patients with medically intractable chronic facial pain of which 19 were treated with Gasserian ganglion stimulation postsuccessful temporary trial. Success, defined as at least $50 \%$ reduction in pain with stimulator active, was achieved in 5 of 7 patients with diagnosed central pain, 5 of 22 for peripheral pain, and none of the 4 with PHN. The authors concluded that Gasserian ganglion stimulation most effectively treated central pain from stroke. More recently, results have been increasingly favorable. The Gasserian ganglion has been a target for neuropathic pain primarily caused by infliction on the trigeminal nerve either following accidental injuries including surgical or trauma, herpes zoster infection, or a result of postinvasive ablation procedure. Kustermans et al (136) retrospectively analyzed 17 patients with refractory TN who after successful 4-week trial were implanted with a neurostimulation electrode at the level of the Gasserian ganglion. A total of 15 out of the 17 patients exhibited at least $50 \%$ pain relief postimplant. Although the pain relief decreased from 6 to 24 months, the authors conclude $44 \%$ of patients maintained long-term pain 
relief after 24 months. Therefore Gasserian ganglion stimulation is promising and should be considered prior to invasive treatments such as motor cortex stimulation or deep brain stimulation.

\section{Future Treatments on the Horizon}

With advancing technology, new devices have been developed that are smaller and take advantage of wireless capabilities. This allows for the implantation of tiny leads without the need for a larger implantable power source. One case report describes efficacy of a supraorbital implantation of 2 octopolar wireless neurostimulators with an external pulse generator for a patient with posttraumatic neuralgia. Stimulation was given at $\mathrm{HF}(10 \mathrm{kHz})$ over the supraorbital nerve and patient reported a decrease in pain from 8 to 2 at both 12- and 24-month follow-up (137). In theory, a smaller wireless device can lead to a less invasive implantation and fewer complications including skin erosion, lead migration, and local pain (78).

As aforementioned, currently there are implantable on-demand wireless microstimulators that affords the patient the ability to actively control stimulation themselves, as needed. Autonomic Technologies Inc. neurostimulation is now referred to as SPG microstimulation therapy and is available in the European Union for the treatment of episodic and chronic $\mathrm{CH}$. Currently, SPG microstimulation remains investigational in the United States. Pietzsch et al (138) reviewed the Pathway $\mathrm{CH}-1$ study by Schoenen et al (130) and concluded that SPG stimulation has positive outcomes in patients with chronic $\mathrm{CH}$ and may provide an overall health care cost savings within 5 years poststimulation. Although this study assumes the results from the Pathway $\mathrm{CH}-1$ study can be generalized to the entire population suffering from $\mathrm{CH}$, it suggests this neuromodulation technique, while providing better health outcomes, can also simultaneously improve cost-efficacy over time.

For SCS, novel technologies are currently being tested to best therapeutically stimulate the active targets. For instance, closed-loop systems have the ability to automatically adjust stimulation levels to maximize the overall time the patient receives the optimal therapeutic dose (139). These advances have the capabilities to be adapted to treat head and facial pain. With innovative technology and an expanding knowledge base, the future for neuromodulation remains promising.

\section{Conclusions}

The nerves of the head and face form an elaborate and often interconnected network. A stimulus affecting one nerve has the ability to cause responses of nearby structures and may mimic symptomatology from other regions. Common first-line therapy primarily consists of oral medications. As many patients continue to progress to chronic states of pain, surely the current treatments are lacking. Historically, interventions such as nerve blocks and surgery served a role in this intractable population. Lately, the field of neuromodulation has become instrumental in this vulnerable subset of treatment failure patients. Neuromodulation has the opportunity to have a longer duration of relief than injections and often has a lower risk profile compared with other surgical procedures, partly owing to the reversibility of the stimulator implantation.

Many patients live with facial pain that is refractory to conservative treatment. As discussed earlier, multiple pathologies have shown positive results with PNS of various targets. For neuromodulation to be effective, the patient must be correctly diagnosed and selectively chosen so that targeted nerve stimulation can allow for a successful outcome. Larger, randomized, controlled trials are required before many of these treatments can be defined as standard of care and evidenced-based medicine. The future of craniofacial nerve stimulation is promising as advances in our overall collective knowledge, as well as in hardware and surgical technique, allow for better outcomes.

Much of the advances in neuromodulation for the head and face will stem from perfecting the techniques previously described and devising ideal treatment plans including optimizing patient selection. Some of the strongest evidence for implantable neuromodulation in facial pain includes ONS for both migraine and occipital neuralgia, and SPG microstimulation for $\mathrm{CH}$ (Table 3). Regarding noninvasive neuromodulation, there is positive evidence for tVNS for both migraines and $\mathrm{CHs}$, as well as combined transcutaneous supraorbital plus supratrochlear nerve stimulation for migraines (Table 3 ).

\section{Acknowledgment}

The authors would like to thank the editorial board of Pain Physician for review and criticism in improving the manuscript. 
Neurostimulation for the Treatment of Chronic Head and Facial Pain

Table 3: Neuromodulation Evidence for Selected Pain Diagnosis Based on Studies Reviewed

\begin{tabular}{|c|c|c|c|c|c|c|c|c|c|}
\hline & Migraine & $\begin{array}{c}\text { Cluster } \\
\text { Headache }\end{array}$ & $\begin{array}{l}\text { Trigeminal } \\
\text { Neuralgia }\end{array}$ & $\begin{array}{l}\text { Trigeminal } \\
\text { Neuropathy }\end{array}$ & $\begin{array}{l}\text { Occipital } \\
\text { Neuralgia }\end{array}$ & $\begin{array}{l}\text { Paroxysmal } \\
\text { Hemicrania }\end{array}$ & $\begin{array}{c}\text { Glosso- } \\
\text { pharyngeal } \\
\text { Neuralgia } \\
\end{array}$ & $\begin{array}{c}\text { Eagle } \\
\text { Syndrome }\end{array}$ & $\begin{array}{c}\text { Burning } \\
\text { Mouth } \\
\text { Syndrome }\end{array}$ \\
\hline Supraorbital & $\mathrm{x}$ & $\mathrm{x}$ & $\mathrm{x}$ & $\begin{array}{l}\text { Level IV }(82, \\
83,84,86)\end{array}$ & $\mathrm{x}$ & $\mathrm{x}$ & $\mathrm{x}$ & $\mathrm{x}$ & $\mathrm{x}$ \\
\hline Infraorbital & $\mathrm{x}$ & $\mathrm{x}$ & $\mathrm{x}$ & \begin{tabular}{|c} 
Level IV (82, \\
$83,84)$ \\
\end{tabular} & $\mathrm{x}$ & $\mathrm{x}$ & $\mathrm{x}$ & $\mathrm{x}$ & $\mathrm{x}$ \\
\hline $\begin{array}{l}\text { SON and } \\
\text { Occipital }\end{array}$ & $\begin{array}{c}\text { Level IV (87, } \\
88)\end{array}$ & $\mathrm{x}$ & $\mathrm{x}$ & $\begin{array}{l}\text { Level IV } \\
(86)\end{array}$ & $\mathrm{x}$ & $\mathrm{x}$ & $\mathrm{x}$ & $\mathrm{x}$ & $\mathrm{x}$ \\
\hline $\begin{array}{c}\text { SON and } \\
\text { Supratrochlear }\end{array}$ & $\begin{array}{l}\text { Level II (89) } \\
\text { [transcutaneous } \\
\text { stim] }\end{array}$ & $\begin{array}{c}\text { Level IV } \\
\quad(90) \\
\text { [lead } \\
\text { implanted] }\end{array}$ & $\mathrm{x}$ & $\mathrm{x}$ & $\mathrm{x}$ & $\mathrm{x}$ & $\mathrm{x}$ & $\mathrm{x}$ & $\mathrm{x}$ \\
\hline $\begin{array}{l}\text { Auriculo- } \\
\text { temporal }\end{array}$ & Level V (92) & $\mathrm{x}$ & $\mathrm{x}$ & $\begin{array}{l}\text { Level IV } \\
\text { (91) }\end{array}$ & $\mathrm{x}$ & $\mathrm{x}$ & $\mathrm{x}$ & $\mathrm{x}$ & $\mathrm{x}$ \\
\hline Halo-Lead & Level V (93) & $\mathrm{x}$ & $\mathrm{x}$ & $\mathrm{x}$ & $\mathrm{x}$ & $\mathrm{x}$ & $\mathrm{x}$ & $\mathrm{x}$ & $\mathrm{x}$ \\
\hline ONS & $\begin{array}{l}\text { Level II (99, } \\
101,102)\end{array}$ & $\begin{array}{l}\text { Level IV } \\
\text { (103) }\end{array}$ & $\mathrm{x}$ & $\mathrm{x}$ & $\begin{array}{c}\text { Level III } \\
(83,97, \\
98)\end{array}$ & Level IV (54) & $\mathrm{x}$ & $\mathrm{x}$ & $\mathrm{x}$ \\
\hline VNS & $\begin{array}{c}\text { Level IV }(104, \\
105,106)\end{array}$ & $\begin{array}{c}\text { Level IV } \\
(105)\end{array}$ & $\mathrm{x}$ & $\mathrm{x}$ & $\mathrm{x}$ & $\mathrm{x}$ & $\mathrm{x}$ & $\mathrm{x}$ & $\mathrm{x}$ \\
\hline tVNS & $\begin{array}{c}\text { Level II } \\
(108,110)\end{array}$ & $\begin{array}{l}\text { Level II } \\
(107,109)\end{array}$ & $\mathrm{x}$ & $\mathrm{x}$ & $\mathrm{x}$ & Level IV (57) & $\mathrm{x}$ & $\mathrm{x}$ & $\mathrm{x}$ \\
\hline HCSCS & $\begin{array}{c}\text { Level IV (111, } \\
115,116)\end{array}$ & $\begin{array}{c}\text { Level IV } \\
(114,116)\end{array}$ & $\begin{array}{l}\text { Level V } \\
\text { (118) }\end{array}$ & $\begin{array}{c}\text { Level IV } \\
(117,118, \\
119)\end{array}$ & $\begin{array}{l}\text { Level IV } \\
(117)\end{array}$ & $\mathrm{x}$ & $\mathrm{x}$ & $\begin{array}{l}\text { Level V } \\
(120)\end{array}$ & $\mathrm{x}$ \\
\hline PNfS & $\begin{array}{c}\text { Level IV (126, } \\
127)\end{array}$ & $\begin{array}{l}\text { Level IV } \\
\text { (127) }\end{array}$ & $\begin{array}{l}\text { Level IV } \\
\text { (122) }\end{array}$ & $\begin{array}{l}\text { Level IV } \\
(121,122)\end{array}$ & $\begin{array}{l}\text { Level IV } \\
(121,125, \\
126,127)\end{array}$ & $\mathrm{x}$ & $\mathrm{x}$ & $\mathrm{x}$ & $\mathrm{x}$ \\
\hline $\begin{array}{c}\text { Temporal } \\
\text { PNfS and } \\
\text { ONS }\end{array}$ & Level V (126) & $\mathrm{x}$ & $\mathrm{x}$ & $\mathrm{x}$ & $\begin{array}{l}\text { Level V } \\
(126)\end{array}$ & $\mathrm{x}$ & $\mathrm{x}$ & $\mathrm{x}$ & $\mathrm{x}$ \\
\hline SPG & $\mathrm{x}$ & $\begin{array}{c}\text { Level II } \\
(130,131, \\
132,133)\end{array}$ & $\mathrm{x}$ & $\begin{array}{c}\text { Level IV } \\
(128,129)\end{array}$ & $\mathrm{x}$ & Level V (54) & $\mathrm{x}$ & $\mathrm{x}$ & $\mathrm{x}$ \\
\hline $\begin{array}{l}\text { Gasserian } \\
\text { Ganglion }\end{array}$ & $\mathrm{x}$ & $\mathrm{x}$ & $\begin{array}{l}\text { Level IV } \\
\text { (136) }\end{array}$ & $\begin{array}{l}\text { Level IV (80, } \\
128)\end{array}$ & $\mathrm{x}$ & $\mathrm{x}$ & $\mathrm{x}$ & $\mathrm{x}$ & $\mathrm{x}$ \\
\hline
\end{tabular}




\section{References}

1. Hunter CW, Stovall B, Chen G, Carlson J, Levy R. Anatomy, pathophysiology and interventional therapies for chronic pelvic pain: A review. Pain Physician 2018; 21:147-167.

2. Deer TR, Mekhail N, Provenzano D, et al. The appropriate use of neurostimulation of the spinal cord and peripheral nervous system for the treatment of chronic pain and ischemic diseases: The Neuromodulation Appropriateness Consensus Committee. Neuromodulation 2014; 17:515-550.

3. Deer TR, Krames E, Mekhail N, et al. The appropriate use of neurostimulation: New and evolving neurostimulation therapies and applicable treatment for chronic pain and selected disease states. Neuromodulation 2014; 17:599-615.

4. Deer TR, Mekhail N, Petersen E, et al. The appropriate use of neurostimulation: Stimulation of the intracranial and extracranial space and head for chronic pain. Neuromodulation 2014; 17:551-570.

5. Bathla G, Hegde AN. The trigeminal nerve: An illustrated review of its imaging anatomy and pathology. Clin Radiol 2013; 68:203-213.

6. Agur AMR, Dalley AF. Grant's Atlas of Anatomy. 14th ed. Philadelphia, PA: Wolters Kluwer; 2017.

7. Drake R, Vogl AW, Mitchell AWM, Tibbitts R, Richardson P. Gray's Atlas of Anatomy E-Book. New York, NY: Elsevier Health Sciences; 2014.

8. Vaisman J, Lopez E, Muraoka NK. Supraorbital and supratrochlear stimulation for trigeminal autonomic cephalalgias. Curr Pain Headache Rep 2014; 18:1-7.

9. Piagkou $M$, Demesticha $T$, Troupis $T$, Vlasis K, Skandalakis P, Makri A, Mazarakis A, Lappas D, Piagkos G, Johnson EO. The pterygopalatine ganglion and its role in various pain syndromes: from anatomy to clinical practice. Pain Practice. 2012; 12:399-412.

10. Robbins MS, Robertson CE, Kaplan E, et al. The sphenopalatine ganglion: Anatomy, pathophysiology, and therapeutic targeting in headache. Headache 2016; 56:240-258.

11. Cesmebasi A, Muhleman MA, Hulsberg $P$, et al. Occipital neuralgia: anatomic considerations. Clin Anat 2015; 28:101-108.

12. Narouze S, Pope JE. Orofacial Pain. In: Benzon HT, Raja SN, Liu SS, Fishman
SM, Cohen SP (eds). Essentials of Pain Medicine. 4th ed. New York, Elsevier, 2018: pp. 183-192.

13. Goadsby PJ, Hoskin KL. The distribution of trigeminovascular afferents in the nonhuman primate brain Macaca nemestrina: A c-fos immunocytochemical study. J Anat 1997; 190:367-375.

14. Schwedt T. Neurostimulation for primary headache disorders. Curr Neurol Neurosci Rep 2009; 9:101-107.

15. Matharu MS, Bartsch T, Ward N, Frackowiak RSJ, Weiner RL, Goadsby PJ. Central neuromodulation in chronic migraine patients with suboccipital stimulators: A PET study. Brain 2004; 127:220-230.

16. Lipton RB, Silberstein SD. Episodic and chronic migraine headache: Breaking down barriers to optimal treatment and prevention. Headache 2015; 55(Suppl 2):103-122.

17. Vos T, Allen C, Arora M, et al. Global, regional, and national incidence, prevalence, and years lived with disability for 310 diseases and injuries, 1990-2015: A systematic analysis for the Global Burden of Disease Study 2015. Lancet 2016; 388:1545-1602.

18. Nye BL, Thadani VM. Migraine and epilepsy: Review of the literature. Headache 2015; 55:359-380.

19. Lipton RB, Bigal ME. Migraine: Epidemiology, impact, and risk factors for progression. Headache 2005; 45(Supp 1): $\mathrm{S}_{3}-\mathrm{S}_{13}$.

20. Arnold M. Headache Classification Committee of the International Headache Society (IHS) The International Classification of Headache Disorders. Cephalalgia 2018; 38:1-211.

21. Katsarava Z, Schneeweiss S, Kurth T, et al. Incidence and predictors for chronicity of headache in patients with episodic migraine. Neurology 2004; 62:788-790.

22. Chen YF, Bramley G, Unwin G, et al. Occipital nerve stimulation for chronic migraine: A systematic review and metaanalysis. PloS One 2015; 10:e0116786.

23. Benoliel R. Trigeminal autonomic cephalgias. Br J Pain 2012; 6:106-123.

24. Fischera M, Marziniak M, Gralow I, Evers $S$. The incidence and prevalence of cluster headache: A meta-analysis of population-based studies. Cephalalgia 2008; 28:614-618.

25. Weaver-Agostoni J. Cluster headache. Am Fam Physician 2013; 88:122-128.
26. Dougherty C. Occipital neuralgia. Curr Pain Headache Rep 2014; 18:411.

27. Choi I, Jeon SR. Neuralgias of the head: Occipital neuralgia. J Korean Med Sci 2016; 31:479-488.

28. Silvestre FJ, Silvestre-Rangil J, LopezJornet P. Burning mouth syndrome: A review and update. Rev Neurol 2015; 60:457-463.

29. Jaaskelainen SK, Woda A. Burning mouth syndrome. Cephalalgia 2017; 37:627-647

30. Rodríguez-de Rivera-Campillo E, LópezLópez J. Evaluation of the response to treatment and clinical evolution in patients with burning mouth syndrome. Med Oral Patol Oral Cir Bucal 2012; 18:e403-e410.

31. Afrin LB. Burning mouth syndrome and mast cell activation disorder. Oral Surg Oral Med Oral Pathol Oral Radiol Endod 2011; 111:465-472.

32. De Giuseppe R, Novembrino C, Guzzi G, Pigatto PD, Bamonti F. Burning mouth syndrome and vitamin $B 12$ deficiency. J Eur Acad Dermatol Venereol. 2011;25(7):869-870.

33. Gurvits GE, Tan A. Burning mouth syndrome. World J Gastroenterol 2013; 19:665-672.

34. Javali MA. Burning mouth syndrome: An enigmatic disorder. Kathmandu Univ Med J (KUMJ) 2013; 11:175-178.

35. McMillan $R$, Forssell $H$, Buchanan JAG, Glenny AM, Weldon JC, Zakrzewska JM. Interventions for treating burning mouth syndrome. Cochrane Database Syst Rev 2016; 11:CDoo2779.

36. Rodríguez-de Rivera-Campillo E, LópezLópez J. Evaluation of the response to treatment and clinical evolution in patients with burning mouth syndrome. Med Oral Patol Oral Cir Bucal 2012; 18:e403-e410.

37. Umezaki Y, Badran BW, Gonzales TS, George MS. Daily left prefrontal repetitive transcranial magnetic stimulation for medication-resistant burning mouth syndrome. Int J Oral Maxillofac Surg 2015; 44:1048-1051.

38. Manzoni GC, Torelli P. Epidemiology of typical and atypical craniofacial neuralgias. Neurol Sci 2005; 26:67.

39. Di Stefano G, La Cesa S, Truini A, Cruccu G. Natural history and outcome of 200 outpatients with classical trigeminal neuralgia treated with carbamazepine or oxcarbazepine in a tertiary centre for 
neuropathic pain. J Headache Pain 2014; 15:1-5.

40. Lettmaier S. Radiosurgery in trigeminal neuralgia. Phys Med 2014; 30:592-595.

41. Devulder JE. Postherpetic ophthalmic neuralgia. Bull Soc Belge Ophtalmol 2002:19-23.

42. Blumenfeld A, Nikolskaya G. Glossopharyngeal neuralgia. Curr Pain Headache Rep 2013; 17:343

43. Soh KB. The glossopharyngeal nerve, glossopharyngeal neuralgia and the Eagle's syndrome current concepts and management. Singapore Med J 1999; 40:659-665

44. Singh $P$, Dehran $M$, Mohan V, Trikha A, Kaur M. Analgesic efficacy and safety of medical therapy alone vs combined medical therapy and extraoral glossopharyngeal nerve block in glossopharyngeal neuralgia. Pain Med 2013; 14:93-102.

45. Dalessio DJ. Diagnosis and treatment of cranial neuralgias. Med Clin North Am 1991; 75:605-615.

46. Lu VM, Goyal A, Graffeo CS, Perry A, Jonker BP, Link MJ. Glossopharyngeal neuralgia treatment outcomes following nerve section, microvascular decompression, or stereotactic radiosurgery: A systematic review and meta-analysis. World Neurosurg 2018; 120:572-582.e7.

47. Pommier B, Touzet G, Lucas C, Vermandel M, Blond S, Reyns N. Glossopharyngeal neuralgia treated by Gamma Knife radiosurgery: Safety and efficacy through long-term follow-up. J Neurosurg 2018; 128:1372-1379.

48. Eagle WW. Elongated styloid process; symptoms and treatment. AMA Arch Otolaryngol 1958; 67:172-176.

49. Eagle WW. Symptomatic elongated styloid process: Report of two cases of styloid process-carotid artery syndrome with operation. Arch Otolaryngol 1949; 49:490-503.

50. Costantinides F, Vidoni G, Bodin C, Di Lenarda R. Eagle's syndrome: Signs and symptoms. Cranio 2013; 31:56-6o.

51. Murtagh RD, Caracciolo JT, Fernandez G. CT findings associated with Eagle syndrome. Am ] Neuroradiol 2001; 22:1401-1402.

52. Mollinedo FT, Esteban SLT, Vega CG, Orcasitas AC, Maguregi AA. Pulsed radiofrequency treatment in a case of Eagle's syndrome. Pain Pract 2013; 13:399-404.

53. Politi M, Corrado T, Tenani G. A rare cause for cervical pain: Eagle's syn- drome. Int J Dentistry 2009:781297.

54. Prakash S, Patell R. Paroxysmal hemicrania: An update. Curr Pain Headache Rep 2014; 18:407.

55. Cittadini E, Matharu MS, Goadsby PJ. Paroxysmal hemicrania: A prospective clinical study of 31 cases. Brain 2008; 131:1142-1155.

56. Morelli N, Mancuso M, Felisati G, et al. Does sphenopalatine endoscopic ganglion block have an effect in paroxysmal hemicrania? A case report. Cephalalgia 2010; 30:365-367.

57. Tso AR, Marin J, Goadsby PJ. Noninvasive vagus nerve stimulation for treatment of indomethacin-sensitive headaches. JAMA Neurol 2017; 74:1266-1267.

58. Rozental JM. Migraine headache and the trigeminal autonomic cephalalgias. In: Benzon HT, Raja SN, Liu SS, Fishman SM, Cohen SP (eds). Essentials of Pain Medicine. 4th ed. New York, Elsevier, 2018: pp. 157-164.

59. Haroutounian S, Finnerup NB. Recommendations for pharmacologic therapy of neuropathic pain. In: Benzon HT, Raja SN, Liu SS, Fishman SM, Cohen SP (eds). Essentials of Pain Medicine. 4th ed. New York, Elsevier, 2018: pp. 445-456.

6o. Bevilaqua-Grossi D, Gonçalves MC Carvalho GF, et al. Additional effects of a physical therapy protocol on headache frequency, pressure pain threshold, and improvement perception in patients with migraine and associated neck pain: A randomized controlled trial. Arch Phys Med Rehabil 2016; 97:866-874.

61. Busch V, Gaul C. Exercise in migraine therapy: Is there any evidence for efficacy? A critical review. Headache 2008 ; 48:890-899.

62. Hosey M, McWhorter JW, Wegener ST. Psychologic interventions for chronic pain. In: Benzon HT, Raja SN, Liu SS, Fishman SM, Cohen SP (eds). Essentials of Pain Medicine. 4th ed. New York, Elsevier, 2018: pp. 539-544.

63. Rozen, TD. Trigeminal neuralgia and glossopharyngeal neuralgia. Neurol Clin 2004; 22:185-206

64. Hsu ES, Wu I, Lai B. Acupuncture. In: Benzon HT, Raja SN, Liu SS, Fishman SM, Cohen SP (eds). Essentials of Pain Medicine. 4th ed. New York, Elsevier, 2018: pp. 545-550.

65. Ashkenazi A, Blumenfeld A, Napchan U et al. Peripheral nerve blocks and trigger point injections in headache management: A systematic review and suggestions for future research. Headache
2010; 50:943-952.

66. Diener HC, Dodick DW, Aurora SK, et al. OnabotulinumtoxinA for treatment of chronic migraine: Results from the double-blind, randomized, placebocontrolled phase of the PREEMPT 2 trial. Cephalalgia 2010; 30:804-814.

67. Simpson DM, Hallett M, Ashman EJ, et al. Practice guideline update summary: Botulinum neurotoxin for the treatment of blepharospasm, cervical dystonia, adult spasticity, and headache Report of the Guideline Development Subcommittee of the American Academy of Neurology. Neurology 2016; 86:1818-1826.

68. Blumenfeld A, Ashkenazi A, Napchan U, et al. Expert consensus recommendations for the performance of peripheral nerve blocks for headaches: A narrative review. Headache 2013; 53:437-446.

69. Robbins MS, Robertson CE, Kaplan E, et al. The sphenopalatine ganglion: Anatomy, pathophysiology, and therapeutic targeting in headache. Headache 2016; 56:240-258.

70. Ho KW, Przkora R, Kumar S. Sphenopalatine ganglion: Block, radiofrequency ablation and neurostimulation: A systematic review. J Headache Pain 2017; 18:118.

71. Kosugi S, Shiotani M, Otsuka Y, et al. Long-term outcomes of percutaneous radiofrequency thermocoagulation of Gasserian ganglion for 2nd- and multiple-division trigeminal neuralgia. Pain Practice 2015; 15:223-228.

72. Lan M, Zipu J, Ying S, Hao R, Fang L. Efficacy and safety of CT-guided percutaneous pulsed radiofrequency treatment of the Gasserian ganglion in patients with medically intractable idiopathic trigeminal neuralgia. J Pain Res 2018; 11:2877-2885.

73. Day M. Neurolysis of the trigeminal and sphenopalatine ganglions. Pain Practice 2001; 1:171-182.

74. Clark SW, Wu C. Evidence for surgical management of facial pain and headache. JHN J 2016; 11:10.

75. Kosharskyy B, Almonte W, Shaparin N, Pappagallo M, Smith $H$. Intravenous infusions in chronic pain management. Pain Physician 2013; 16:231-249.

76. Shirahige L, Melo L, Nogueira F, Rocha S, Monte-Silva K. Efficacy of noninvasive brain stimulation on pain control in migraine patients: A systematic review and meta-analysis. Headache 2016; 56:1565-1596. 
77. Lefaucheur JP, André-Obadia N, Antal A . Evidence-based guidelines on the therapeutic use of repetitive transcranial magnetic stimulation (rTMS). Clin Neurophysiol 2014; 125:2150-2206.

78. Maniam R, Kaye AD, Vadivelu N, Urman RD. Facial pain update: Advances in neurostimulation for the treatment of facial pain. Curr Pain Headache Rep 2016; $20: 24$.

79. Manchikanti L, Hirsch JA, Cohen SP, et al. Assessment of methodologic quality of randomized trials of interventional techniques: Development of an interventional pain management specific instrument. Pain Physician 2014; 17:E263-E290.

8o. Taub E, Munuz M, Tasker RR. Chronic electrical stimulation of the Gasserian ganglion for the relief of pain in a series of 34 patients. J Neurosurg 1997; 86:197-202.

81. Slavin KV, Wess C. Trigeminal branch stimulation for intractable neuropathic pain: Technical note. Neuromodulation 2005; 8:7-13

82. Johnson MD, Burchiel KJ. Peripheral stimulation for treatment of trigeminal postherpetic neuralgia and trigeminal posttraumatic neuropathic pain: A pilot study. Neurosurgery 2004; 55:135-142.

83. Slavin KV, Colpan ME, Munawar N, Wess C, Nersesyan H. Trigeminal and occipital peripheral nerve stimulation for craniofacial pain: A single-institution experience and review of the literature. Neurosurg Focus 2006; 21: E5.

84. Stidd DA, Wuollet AL, Bowden K, et al. Peripheral nerve stimulation for trigeminal neuropathic pain. Pain Physician 2012; 15:27-33.

85. McRoberts WP. Optimizing stimulation in a case of facial pain through "crosstalk" of peripheral and central leads: A case report. Neuromodulation 2016; 19:885-888.

86. Amin S, Buvanendran A, Park KS, Kroin JS, Moric M. Peripheral nerve stimulator for the treatment of supraorbital neuralgia: A retrospective case series. Cephalalgia 2008; 28:355-359.

87. Reed KL, Will KR, Conidi F, Bulger R. Concordant occipital and supraorbital neurostimulation therapy for hemiplegic migraine; initial experience; a case series. Neuromodulation: Technology at the Neural Interface. 2015 Jun;18(4):297-304.

88. Hann S, Sharan A. Dual occipital and supraorbital nerve stimulation for chronic migraine: A single-center expe- rience, review of literature, and surgical considerations. Neurosurg Focus 2013; 35:E9.

89. Schoenen J, Vandersmissen B, Jeangette $S$, et al. Migraine prevention with a supraorbital transcutaneous stimulator: A randomized controlled trial. Neurology 2013; 80:697-704.

90. Vaisman J, Markley H, Ordia J, Deer T. The treatment of medically intractable trigeminal autonomic cephalalgia with supraorbital/supratrochlear stimulation: A retrospective case series. Neuromodulation 2012; 15:374-380.

91. Rodriguez-Lopez MJ, Fernandez-Baena M, Aldaya-Valverde C. Management of pain secondary to temporomandibular joint syndrome with peripheral nerve stimulation. Pain Physician 2015; 18:E229-E236.

92. Simopoulos T, Bajwa Z, Lantz G, Lee S, Burstein R. Implanted auriculotemporal nerve stimulator for the treatment of refractory chronic migraine. Headache 2010; 50:1064-1069.

93. Haider NR, Deer TR. Stimulation of the peripheral nervous system: Occipital techniques for the treatment of occipital neuritis and transformed migraine. In: Deer TR, Pope JE (eds). Atlas of Implantable Therapies for Pain Management. New York, NY, Springer, 2016: pp. 235-242

94. Goadsby PJ, Bartsch T, Dodick DW. Occipital nerve stimulation for headache: Mechanisms and efficacy. Headache 2008; 48:313-318.

95. Matharu MS, Bartsch T, Ward N, Frackowiak RS, Weiner R, Goadsby PJ. Central neuromodulation in chronic migraine patients with suboccipital stimulators: A PET study. Brain 2004; 127:220-230.

96. Magis D, Bruno MA, Fumal A, et al. Central modulation in cluster headache patients treated with occipital nerve stimulation: An FDG-PET study. BMC Neurol 2011; 11:25.

97. Weiner RL, Reed KL. Peripheral neurostimulation for control of intractable occipital neuralgia. Neuromodulation 1999; 2:217-221.

98. Kapural L, Mekhail N, Hayek SM, Stanton-Hicks M, Malak O. Occipital nerve electrical stimulation via the midline approach and subcutaneous surgical leads for treatment of severe occipital neuralgia: A pilot study. Anesth Analg 2005; 101:171-174.

99. Saper JR, Dodick DW, Silberstein SD, McCarville S, Sun M, Goadsby PJ. Occipital nerve stimulation for the treatment of intractable chronic migraine headache: ONSTIM feasibility study. Cephalalgia 2011; 31:271-285.

100. Schwedt TJ. Occipital nerve stimulation for chronic migraine--interpreting the ONSTIM feasibility trial. Cephalalgia 2011; 31:262-263.

101. Silberstein SD, Dodick DW, Saper J, et al. Safety and efficacy of peripheral nerve stimulation of the occipital nerves for the management of chronic migraine: Results from a randomized, multicenter, double-blinded, controlled study. Cephalalgia 2012; 32:1165-1179.

102. Dodick DW, Silberstein SD, Reed KL, et al. Safety and efficacy of peripheral nerve stimulation of the occipital nerves for the management of chronic migraine: long-term results from a randomized, multicenter, double-blinded, controlled study. Cephalalgia 2015; 35:344-358.

103. Burns B, Watkins L, Goadsby PJ. Treatment of medically intractable cluster headache by occipital nerve stimulation: Long-term follow-up 13 patients. Cephalalgia 2007; 27:1190.

104. Lenaerts ME, Oommen KJ, Couch JR, Skaggs $V$. Can vagus nerve stimulation help migraine? Cephalalgia 2008; 28:392-395.

105. Mauskop A. Vagus nerve stimulation relieves chronic refractory migraine and cluster headaches. Cephalalgia 2005; 25:82-86.

106. Cecchini AP, Mea E, Tullo V, et al. Vagus nerve stimulation in drug-resistant daily chronic migraine with depression: Preliminary data. Neurol Sci 2009; 30:101-104.

107. Silberstein SD, Mechtler LL, Kudrow DB, et al. Non-invasive vagus nerve stimulation for the acute treatment of cluster headache: findings from the randomized, double-blind, sham-controlled ACT1 study. Headache 2016; 56:1317-1332.

108. Silberstein SD, Calhoun AH, Lipton RB, et al. Chronic migraine headache prevention with noninvasive vagus nerve stimulation: The EVENT study. Neurology 2016; 87:529-538.

109. Gaul C, Diener HC, Silver N, et al. Non-invasive vagus nerve stimulation for prevention and acute treatment of chronic cluster headache (PREVA): A randomised controlled study. Cephalalgia 2016; 36:534-546.

110. Straube A, Ellrich J, Eren O, Blum B, Ruscheweyh R. Treatment of chronic migraine with transcutaneous stimulation of the auricular branch of the vagal nerve (auricular t-VNS): A randomized, monocentric clinical trial. J Headache 
Pain 2015; 16:63.

111. De Agostino R, Federspiel B, Cesnulis E, Sandor PS. High-cervical spinal cord stimulation for medically intractable chronic migraine. Neuromodulation 2015; 18:289-296; discussion 296.

112. Wolter T, Kaube H, Mohadjer M. High cervical epidural neurostimulation for cluster headache: Case report and review of the literature. Cephalalgia 2008; 28:1091-1094.

113. Elahi F, Reddy C. High cervical epidural neurostimulation for post-traumatic headache management. Pain Physician 2014; 17: $E_{537}-E_{541}$.

114. Wolter T, Kiemen A, Kaube H. High cervical spinal cord stimulation for chronic cluster headache. Cephalalgia 2011; 31:1170-1180.

115. Arcioni R, Palmisani S, Mercieri M, et al. Cervical $10 \mathrm{kHz}$ spinal cord stimulation in the management of chronic, medically refractory migraine: A prospective, open-label, exploratory study. Eur ] Pain 2016; 20:70-78.

116. Lambru G, Trimboli M, Palmisani S, Smith T, Al-Kaisy A. Safety and efficacy of cervical $10 \mathrm{kHz}$ spinal cord stimulation in chronic refractory primary headaches: A retrospective case series. J Headache Pain 2016; 17:66.

117. Tomycz ND, Deibert CP, Moossy J. Cervicomedullary junction spinal cord stimulation for head and facial pain. Headache 2011; 51:418-425.

118. Rajashekar D, Tambirajoo K, Franceschini P, Eldridge P. Long-term outcomes of high cervical spinal cord stimulation in the management of neuropathic facial pain. Int J Surg 2017; 47:S10.

119. Velásquez $C$, Tambirajoo K, Franceschini P, Eldridge PR, Farah JO. Upper cervical spinal cord stimulation as an alternative treatment in trigeminal neuropathy. World Neurosurg 2018; 114:e641-e646.

120. Papa A, Ferrara M, Buonanno P, Santoro V, Servodio C, Servillo G. A novel approach with spinal cord stimulation for the treatment of chronic pain in Eagle's syndrome: A case report. Chron Pain Manag CPMT-112. 2018;
DOI:10.29011/2576-957X/100012.

121. Klein J, Sandi-Gahun S, Schackert G, Juratli TA. Peripheral nerve field stimulation for trigeminal neuralgia, trigeminal neuropathic pain, and persistent idiopathic facial pain. Cephalalgia 2016; 36:445-453.

122. Jakobs $M$, Unterberg $A$, Treede RD, Schuh-Hofer S, Ahmadi R. Subcutaneous trigeminal nerve field stimulation for refractory trigeminal pain: A cohort analysis. Acta Neurochir (Wien) 2016; 158:1767-1774.

123. Yakovlev AE, Resch BE. Treatment of chronic intractable atypical facial pain using peripheral subcutaneous field stimulation. Neuromodulation 2010; 13:137-140.

124. Lipov EG, Joshi JR, Sanders S, Slavin KV. Use of peripheral subcutaneous field stimulation for the treatment of axial neck pain: A case report. Neuromodulation 2009; 12:292-295.

125. Kouroukli I, Neofytos D, Panaretou V, et al. Peripheral subcutaneous stimulation for the treatment of intractable postherpetic neuralgia: Two case reports and literature review. Pain Practice 2009; 9:225-229.

126. Deshpande KK, Wininger KL. Feasibility of combined epicranial temporal and occipital neurostimulation: Treatment of a challenging case of headache. Pain Physician 2011; 14:37-44.

127. Verrills P, Rose R, Mitchell B, Vivian D, Barnard A. Peripheral nerve field stimulation for chronic headache: 60 cases and long-term follow-up. Neuromodulation 2014; 17:54-59.

128. William A, Azad TD, Brecher E, et al. Trigeminal and sphenopalatine ganglion stimulation for intractable craniofacial pain: Case series and literature review. Acta Neurochir 2016; 158:513-520.

129. Elahi F, Reddy CG. Sphenopalatine ganglion electrical nerve stimulation implant for intractable facial pain. Pain Physician 2015; 18:E403-E409.

130. Schoenen J, Jensen RH, Lanteri-Minet $M$, et al. Stimulation of the sphenopalatine ganglion (SPG) for cluster headache treatment. Pathway $\mathrm{CH}-1$ : A randomized, sham-controlled study. Cephalalgia 2013; 33:816-830.

131. Jürgens TP, Barloese M, May $A$, et al. Long-term effectiveness of sphenopalatine ganglion stimulation for cluster headache. Cephalalgia 2017; 37:423-434.

132. Barloese M, Petersen A, Stude P, Jürgens $T$, Jensen RH, May A. Sphenopalatine ganglion stimulation for cluster headache, results from a large, openlabel European registry. J Headache Pain 2018; 19:6.

133. Schytz HW, Barløse M, Guo S, et al. Experimental activation of the sphenopalatine ganglion provokes cluster-like attacks in humans. Cephalalgia 2013; 33:831-841.

134. Jürgens TP, Schoenen J, Rostgaard J, et al. Stimulation of the sphenopalatine ganglion in intractable cluster headache: Expert consensus on patient selection and standards of care. Cephalalgia 2014; 34:1100-1110.

135. Schoenen J. Sphenopalatine ganglion stimulation in neurovascular headaches. Prog Neurol Surg 2015; 29:106-116.

136. Kustermans L, Van Buyten JP, Smet I, Coucke W, Politis C. Stimulation of the Gasserian ganglion in the treatment of refractory trigeminal neuropathy. J Craniomaxillofac Surg 2017; 45:39-46.

137. Van Buyten JP, Smet I, Devos M, Vanquathem N. High frequency supraorbital nerve stimulation with a novel wireless minimally invasive device for posttraumatic neuralgia: A case report. Pain Practice 2019; 19:435-439.

138. Pietzsch JB, Garner A, Gaul C, May A. Cost-effectiveness of stimulation of the sphenopalatine ganglion (SPG) for the treatment of chronic cluster headache: A model-based analysis based on the Pathway $\mathrm{CH}-1$ study. J Headache Pain 2015; 16:48.

139. Russo M, Cousins MJ, Brooker C, et al. Effective relief of pain and associated symptoms with closed-loop spinal cord stimulation system: Preliminary results of the Avalon study. Neuromodulation 2018; 21:38-47. 
